\title{
Tradition and Fermentation Science of prohok, an ethnic fermented fish product of Cambodia
}

\author{
Karen LeGrand ${ }^{1,2,3^{*}} \mathbb{D}$, Buntong Borarin ${ }^{2}$ and Glenn M. Young ${ }^{1}$
}

\begin{abstract}
Cambodian foods are increasingly consumed outside Southeast Asia, yet are the subject of remarkably few reports. The Khmer culture and culinary traditions of Cambodian people, both historical and contemporary, depend most heavily on the fermented fish product prohok (ษึ一ุก) as an essential ingredient in a wide variety of dishes. The aim of this report is to better understand the traditions, production methods, and uses of prohok as well as the retention of this essential flavoring and nutritional component of Khmer cuisine. The reported findings include how fish preservation developed to accommodate Cambodia's unique naturally occurring hydrological phenomena and has influenced the ethnic identity and social structure of Khmer people. Commercial and home production of prohok is observed to have socioeconomic and nutritional impact on people. The uses of prohok in main dishes, sauces, soups, and side dishes are explored.

Furthermore, this report investigates and reviews the underlying microbiology and chemistry that takes place during traditional fermentations of fish to produce prohok. This foundational knowledge serves as a basis for additional scientific studies to further investigate prohok fermentations with the goal to better understand factors that contribute to the unique regional variation of aromas, textures, and flavors produced by traditional practitioners and beloved by Khmer people.
\end{abstract}

Keywords: Khmer, Traditional fermentation, Fermented fish, Food culture, Tonle Sap, Prohok

\section{Introduction}

Ethnic foods are increasingly consumed and becoming more recognized outside the regions in which they originated $[1-3]$. This is particularly true of fermented ethnic foods which, throughout history and across cultures, have been an important part of human tradition. Historically, fermentation has been an appropriate technique to increase food availability in times of scarcity [4]. It is a relatively efficient, low-cost, low-energy process that increases shelf life and decreases the need for other forms of food preservation. As food became more plentiful over time, however, the rationale of food preservation shifted. Culinary practices today reflect ethnic traditions and retain the historic flavor qualities derived from

\footnotetext{
* Correspondence: klegrand@sierracollege.edu

1 University of California, Davis, College of Agricultural and Environmental Sciences, One Shields Way, Davis, CA 95616, USA

${ }^{2}$ Royal University of Agriculture, Division of Research and Extension, Dangkor District, PO Box 2696, Phnom Penh, Cambodia

Full list of author information is available at the end of the article
}

incorporating various fermented foods. The desirable tart and pungent flavors have become so embedded within culinary traditions that fermented foods are considered by many an essential part of the diet.

Traditional knowledge about fermentation technologies and culinary uses for fermented foods have been passed on and refined through generations [4]. These highly valuable cultural traditions reflect the technical, social and economic situation of the region in which specific food products derived. Yet reports of the history, production methods, culinary uses, and cultural significance of traditional fermented foods are limited, particularly outside the region from which they originated. Notably scant are accounts of the wide variety of traditional foods and culinary traditions of the Khmer people of the Kingdom of Cambodia in Southeast Asia. Khmer people are one of the oldest ethnic groups in Southeast Asia and are the largest ethnic group of Cambodia, comprising approximately $90 \%$ of the total population of the

(c) The Author(s). 2020 Open Access This article is distributed under the terms of the Creative Commons Attribution 4.0 International License (http://creativecommons.org/licenses/by/4.0/), which permits unrestricted use, distribution, and 
lower Mekong basin and central plains (Fig. 1). Khmer foods are increasingly consumed in other regions of the world, particularly those with significant Khmer populations $[5,6]$. Yet remarkably few reports focused on Khmer food exist. Khmer people, both historical and contemporary, depend most heavily on the fermented fish product prohok (sometimes also spelled prahok or prohoc, Чษบุก) as an essential ingredient in a wide variety of dishes. This report explores Cambodia's regional geography and history to highlight the cultural significance of fish preservation and better understand the traditions, production methods, and uses of prohok as well as the retention of this essential flavoring and nutritional component of Khmer cuisine.

\section{Materials and methods}

Semi-structured interviews were conducted among domestic people, chefs, consumers, producers, and sellers of prohok. The interviews were conducted by personal visits, as well as remotely by telephone. Additionally, books, online databases, and scientific publications were investigated to gather the required data. The pictures presented in this work were taken by the authors during interviews in the two largest cities in Cambodia, Phnom

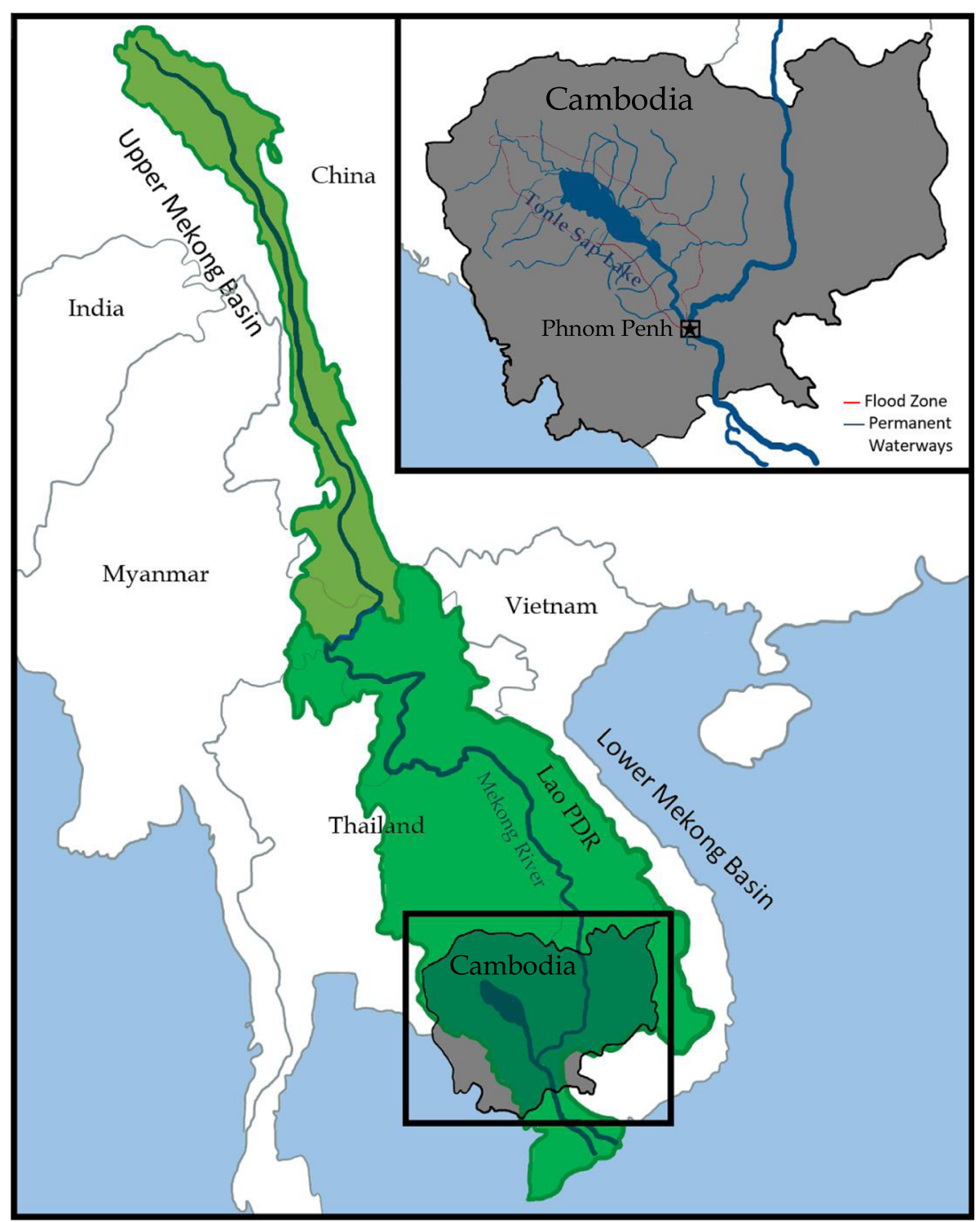

Fig. 1 Regional map indicating the Mekong River Basin. The Upper Mekong River Basin (light green) begins in China and continues through part of Myanmar. The Lower Mekong River Basin (dark green) continues south through Lao PDR, Thailand, Cambodia, and Vietnam. Inset highlights the vast area of Cambodia that is affected by the seasonal flow of water through the Mekong-Tonle Sap hydrological system. Blue indicates permanent waterways. The red line indicates the boundaries of the vast flood zone 
Penh and Battambang. The pictures of the prohok-based dishes were taken after preparation.

\section{Results and discussion}

Diet, nutrition, and prohok (โษนุก) in Cambodia

The diet of the Khmer people of Cambodia relies primarily on rice and fish [7]. Cambodians are one of the highest consumers of fish and other aquatic animals per capita in the world, with fish and fish products contributing nearly $21 \%$ of the total food intake $[8,9]$. Due to the seasonal availability of fish, there has been strong historical incentive to preserve fish using efficient, low cost, low energy processes. Traditionally, prohok was an essential part of Cambodian diets because it was vital to the nutrition and food security of rural families. It is the primary source of animal protein and a significant contributor of dietary iron for Cambodians (76 and 37\%, respectively) $[7,10]$. It is also known to be an important contributor of essential fatty acids, vitamins, and minerals $[8,10,11]$. Many prohok dishes are most enjoyed with a variety of vegetables, a combination that has the added benefit of improving the nutritional quality of Cambodian food by increasing the bioavailability of nutrients in prohok including protein, Vitamin A, calcium, iron, zinc, and iodine [12-15]. Prohok is such a vital part of the diet that Cambodians consume an estimated $18 \mathrm{~g}$ prohok per capita per day [16]. While historically other sources of protein may not have been available in the dry season, in modern Cambodia, advancements in agricultural technology and increases in importation of other animal products have made other sources of protein more readily available. Yet, the traditional incentive to process fish and increase shelf life without preservation technology such as refrigeration persists. Prohok continues to be a vital and widely consumed component of the Cambodian diet that is cherished for its powerful umami flavor qualities in a wide variety of sauces, dips, soups, and main dishes.

Prohok is a part of life and flavor.

$$
\text { “Interview, April 7, 2018” }
$$

You used to eat it because it's all you have, but now it is a necessity in the culture. It's always been there.

“Interview, April 12, 2018”

\section{Cambodia: historical, geographical and seasonal origins of prohok}

To gain context for why prohok is integral to Cambodian food culture, one must consider the geography of the region and how it contributes enormously to Cambodia's national identity. The central region of Cambodia encompasses the Mekong-Tonle Sap hydrological system, which is by far the largest in Southeast Asia (Fig. 1). This remarkable scientific phenomenon is part of the Mekong River Basin which encompasses most of Cambodia and spans across six countries from its origin in China before reaching the South China Sea. Within the Basin, the Mekong River forms the international border between Myanmar and Laos as well as between Laos and Thailand before it continues into Cambodia and through Vietnam to the Sea. In Cambodia, the seasonal flow of the Mekong River is responsible for the unique ecology of the region. During the rainy season, the Mekong River causes the intersecting Tonle Sap River to reverse its flow and flood the area surrounding Tonle Sap Lake. This unique phenomenon results in an inland sea that occupies a massive portion of the central region of Cambodia (10,000-15,000 km² / 3861-5792 $\mathrm{mi}^{2}$ ). Tonle Sap Lake, also known as the "Great Lake", and the surrounding seasonal flood plains are among the world's most fertile breeding grounds for freshwater fish. This area is considered one of the world's ecological hotspots and most productive inland fisheries. Rich in biodiversity, it harbors in excess of 500 fish species, more than 200 of which depend on the seasonal flood plains to provide environments for breeding [17-21]. This unique hydrologic phenomenon has formed the cultural foundation of Cambodia and its people.

Anchored in the centuries-old Khmer culture, food systems and life in Cambodia revolve around the seasonal abundance of fish that follows the flux of the Great Lake. Illustrating the contemporary importance of the MekongTonle Sap hydrologic system, the lake alone (excluding the surrounding waterways) supplies more than $60 \%$ of Cambodia's total fish catch. During the rainy season, from May to October, the area of maximum flooding around the lake supports over 1.2 million people who live in stiltsupported houses or floating villages and directly depend on fishing for their livelihoods [11, 18, 19, 22, 23]. The rainy season ends in November and water levels recede throughout the dry season that extends through April. During this time, the area of Tonle Sap Lake reduces 70$80 \%$, and the flood plains become semi-arid. The vast majority of the annual fish harvest is caught from December through March, as water levels recede during the dry season and fish populations become more condensed in smaller bodies of water, making them easier to catch. This seasonal ecology has influenced the historic traditions developed by Khmer people that remain an integral part of Cambodian society and Khmer food culture.

\section{Ethnic significance and socioeconomic implications of prohok}

The rich history and culture of Cambodia is tightly interwoven with the ebb and flow of the Tonle Sap floodplain 
and the seasonal rainfall. Socioeconomics and the way of life for the majority of Khmer families have been shaped around the routine of cultivating rice during the rainy season, processing and preserving fish during the short peak fishing season, and growing or foraging vegetables. A traditional part of ethnic family living, particularly in rural communities, is structured around planting, harvesting, and processing seasons. Ethnic traditions have been developed around peak fishing times when thousands of Cambodians travel to the Tonle Sap Lake, the Mekong River, and other waterways to trade rice for fish, to fish themselves, or to work as fish processors and laborers to preserve fish primarily in the form of prohok. During this time of abundance, entire families work together to assist with processing, and prohok production businesses hire many temporary laborers. Processing and sale of prohok is an important source of income, particularly for families or widows with low earning potential from other sources of income. Women and children are actively involved, and an increasing number have also taken up vegetable cultivation as a way to diversify diets and provide additional income. Primary and secondary school children learn the art of fish preservation by working in their spare time to perform some of the processing functions in small-scale family businesses. Both historically and contemporarily, this concentrated effort helps pass traditional knowledge from generation to generation and ensure fish products are available throughout the dry season.

In today's society, amidst an influx of other imported and mass-produced food products, the societal traditions built around prohok, rice, and vegetable production in Cambodia remain steadfast. Even as economic development brings new types of foods and modern food processing technologies to Cambodia, local prohok and vegetable producer's traditional knowledge and experience is greatly valued. The variations in prohok produced in different regions of the country result in distinct sensory characteristics that are preferentially desired by consumers. Consumers also prefer locally produced vegetables over imported products [24, 25]. Some fermented fish products are manufactured using modern techniques that include mineral acid or alkali treatment to replace traditional microbial-based fermentation. While more modern methods produce consistent quality and resemble traditionally produced products, consumers report the flavor and other important sensory qualities are not comparable. Local consumers describe a chemical taste that is not fresh or acceptable and emphasize the importance of preserving traditional small-scale fermentation techniques. The unique flavor qualities of the wide variety of prohok products drive consumers to primarily buy from people they know. Even in urban settings, people who have migrated from rural communities seek by word-of-mouth the characteristics of prohok produced in the region from which they originated. Outlets and specialty markets that carry regionallyspecific domestic prohok and vegetable products continue to thrive because locally-derived products made using traditional and chemical-free methods are preferentially consumed over industrially processed or imported products $[24,25]$. This is particularly evident in the capital city of Phnom Penh where marketers meet consumer demand by supplying prohok from producers located throughout the country (Fig. 2).

One notable adaptation to traditional prohok production practices has arisen with the advent of modern modes of transportation. Traditionally, communities coordinated together during the peak fishing season to
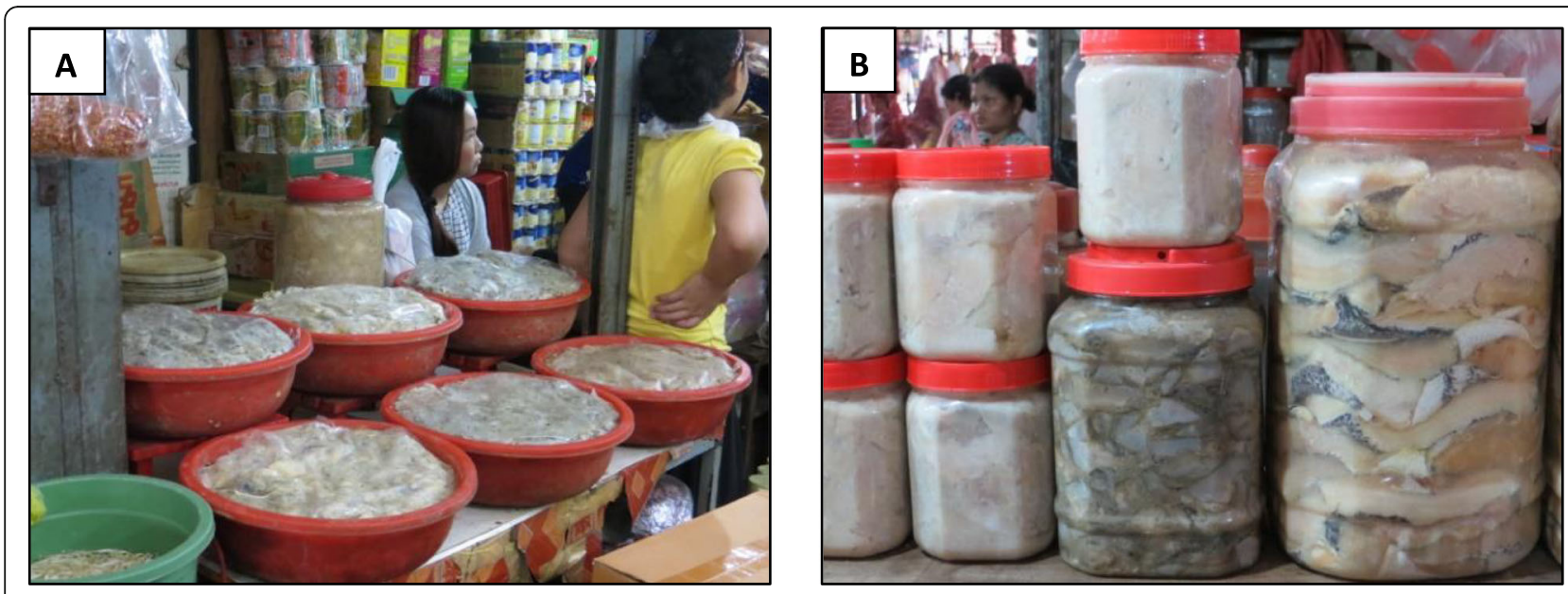

Fig. 2 Retail shops in Phnom Penh sell multiple types of prohok. Sellers in the capital city obtain supplies from different regions throughout Cambodia to meet the demand of urban consumers. At urban markets, prohok can be purchased in different ways. a Bulk purchases can be made from retailers who sell portions from bulk containers. $\mathbf{b}$ Pre-packaged containers of different sizes can be purchased from other retailers. Photo credit Karen LeGrand 
arrange caravans to the nearest waterway, sometimes 60 $\mathrm{km}$ away. Ethnic traditions of many families included traveling in oxcarts, sometimes for a week, to target one of the two-week periods of peak fishing activity that preceded a full moon. Fish would be purchased and processed before families make the return trip home. However, the convenience of motorbikes, cars, and trucks has taken hold, and middlemen have developed a market for delivering fish during the peak season. Some producers who live in areas of Cambodia without access to the country's many waterways no longer embark on the traditional journey. Amidst this change, however, the high value placed on the regional sensory characteristics of prohok prevails. Most prohok continues to be produced regionally. Since most urban areas are populated by people who migrated from the countryside, there is a huge urban demand for the wide variety of distinct flavors produced in different areas of Cambodia. Retailers in the larger cities of Cambodia carry prohok produced throughout Cambodia which highlights the skill local producers have to consistently obtain specifically desirable flavors. Traditional practitioners and experienced fish dealers in rural communities continue to play very important roles in the changing food system of Cambodia.

\section{Types of prohok and traditional methods of preparation} There are two main types of prohok. Prohok ch'oeung

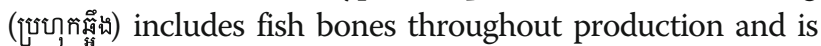
made with 15-20\% salt. In contrast, prohok sach (โษบุกต่อิ่) is made by first discarding the fish bones and using $25-30 \%$ salt. While the culinary uses of prohok ch'oeung and prohok sach are similar, cost is the primary consideration used to determine which type of prohok is used in a particular recipe. While prohok sach is preferred for many recipes, prohok ch'oeung is sometimes substituted. One kilogram of prohok ch'oeung is approximately US\$2.50 and $1 \mathrm{~kg}$ of prohok sach is approximately US\$7.50. Consequently, it is not always economically feasible to use prohok sach.

Based on annual fish catch estimates from the Tonle Sap region, approximately 455,000 tons in 2012, 528,000 tons in 2013, and 505,000 tons in 2014 of fish were caught in Cambodia and used to make prohok or consumed fresh [24]. Among the fish caught, at least half are small-size- or low-market-value fish [19, 22, 26-28]. Prohok ch'oeung is made from these small $(10-17 \mathrm{~cm})$, fast growing, opportunistic species, which are mainly from the Cyprinidae family. They migrate into the flood plain during the rainy season where they reproduce prolifically and are easily caught when the water recedes in the dry season. Many species are known by the local name, trey riel (โดีค่ิญ), which is literally translated "fish money," a name that highlights the economic significance of transforming these fish with low direct consumer preference and little or no direct commercial value into highly desirable prohok (Fig. 3). Trey riel includes several species of Cyprinidae including Henicorhynchus siamensis, H. cryptopogon, and Thynnichthys thynnoides. Another small fish used for making prohok ch'oeung is Rasbora urophthalmoides, locally known as changva

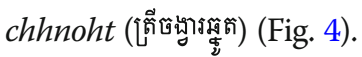

The other type of prohok, prohok sach (๘ษบุกต่ษิ), is made primarily from a large fish commonly known as

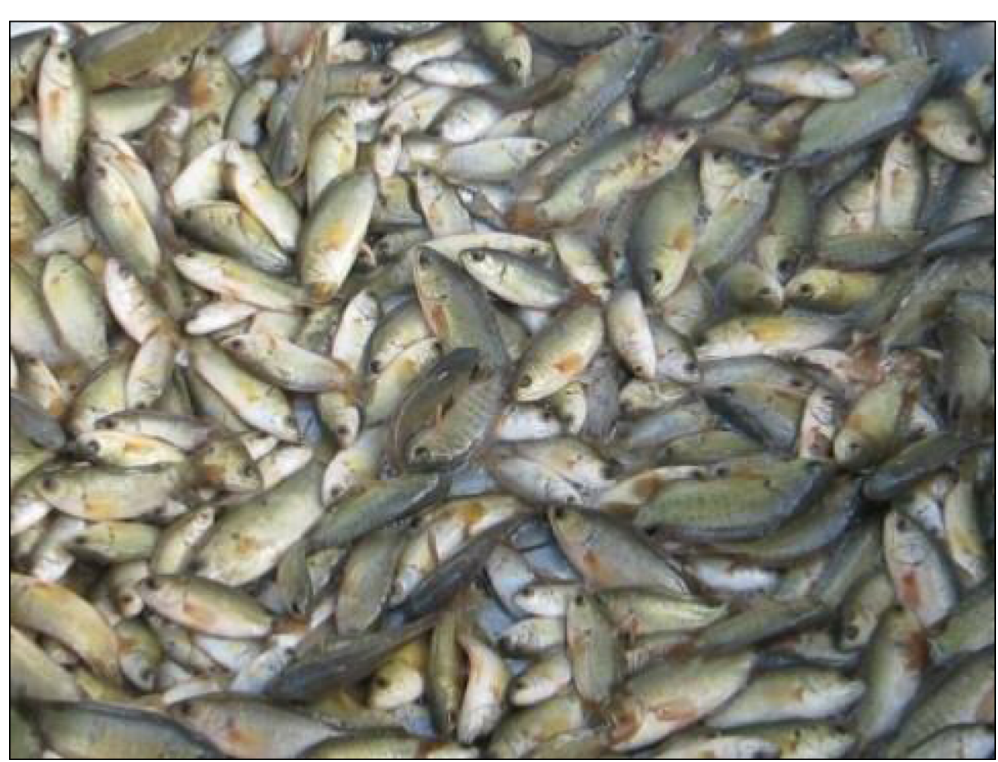

Fig. 3 Small fish from the Cyprinidae family. Ranging from 10-17 cm, these fish have very little direct commercial value. Their local name in

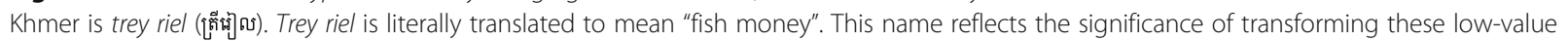

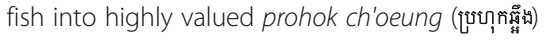




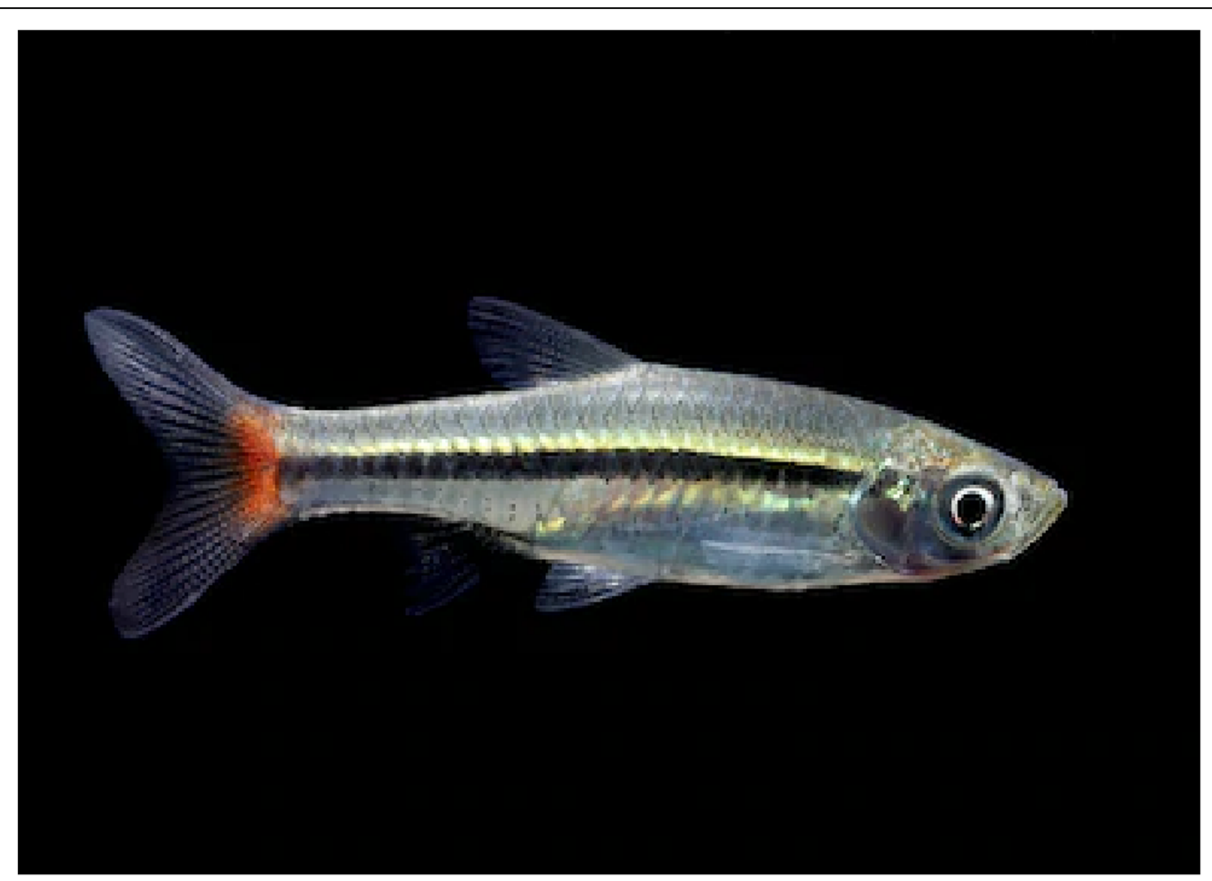

Fig. 4 Small fish from the Rasbora family. A fully mature individual has a standard length of $5 \mathrm{~cm}$. This small size makes Rasbora good for making

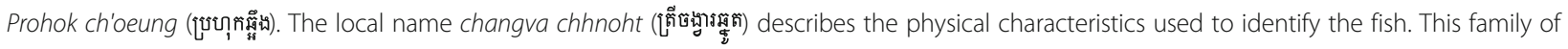
fish has a central dark stripe (chhnoht) and shape of a row boat oar (changva) and is well known to Khmer people by this name

snakehead (Fig. 5). Snakehead fish are locally referred to

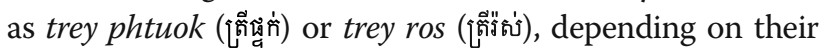
size, and are part of the Channidae family [29-31]. Snakehead fish are a vitally important species in Cambodia because their seasonal migratory patterns make them widely accessible to Cambodian people, particularly those living in areas away from the main waterways. Snakehead fish migrate from the main rivers and lakes of the Tonle Sap hydrological system into the flood plains during the rainy season where they favor stagnant, shallow, muddy waters. During the dry season, as the fresh water recedes from the plains and other fish migrate back into the main bodies of water, snakehead fish can survive longer than other species in outlying areas by burrowing in the bottom mud of lakes, canals, and swamps. This makes snakehead fish more readily available to people away from the main waterways. The increased accessibility during certain parts of the year makes it possible for snakehead fish to be consumed fresh or preserved in the form of prohok sach.

Both prohok ch'oeung and prohok sach are made by first removing the heads, scaling, and cleaning the fish (Fig. 6). Traditionally, descaling and cleaning were done by placing the fish in a flat basket at the edge of the river and stepping on the fish until the scales are washed away in the river current. While this practice remains in some areas, modern tools are available that remove the heads and scales. Prohok ch'oeung is made with the tiny bones of the small fish which soften during fermentation. Prohok sach is made by either filleting the large snakehead fish and discarding the bones or chopping the fish into steaks. The prepared fish are then mixed with salt to a relatively low concentration, commonly $4-5 \%$, and soaked in baskets overnight (Fig. 7). This early fermentation process produces a highly desirable by-product. Some producers collect this liquid to make teuk trey ( ̊ึกโุี ), one type of fish sauce that is considered more delicious than other types of fish sauces because it has a distinct, pleasantly mild, and fresh taste compared to other types produced using longer fermentations. After the teuk trey is collected, the fish are removed from the baskets. Some types of prohok are made by drying the fish in the sun and crushing or grinding them with a mortar or sometimes even the feet. Alternatively, some producers do not drain off the initial teuk trey fermentation liquid and rather continue the process by packing the fish and salt mixture into an airtight container. Whether the fish are dried or the early fermentation liquid is carried forward, the fish are salted again with 


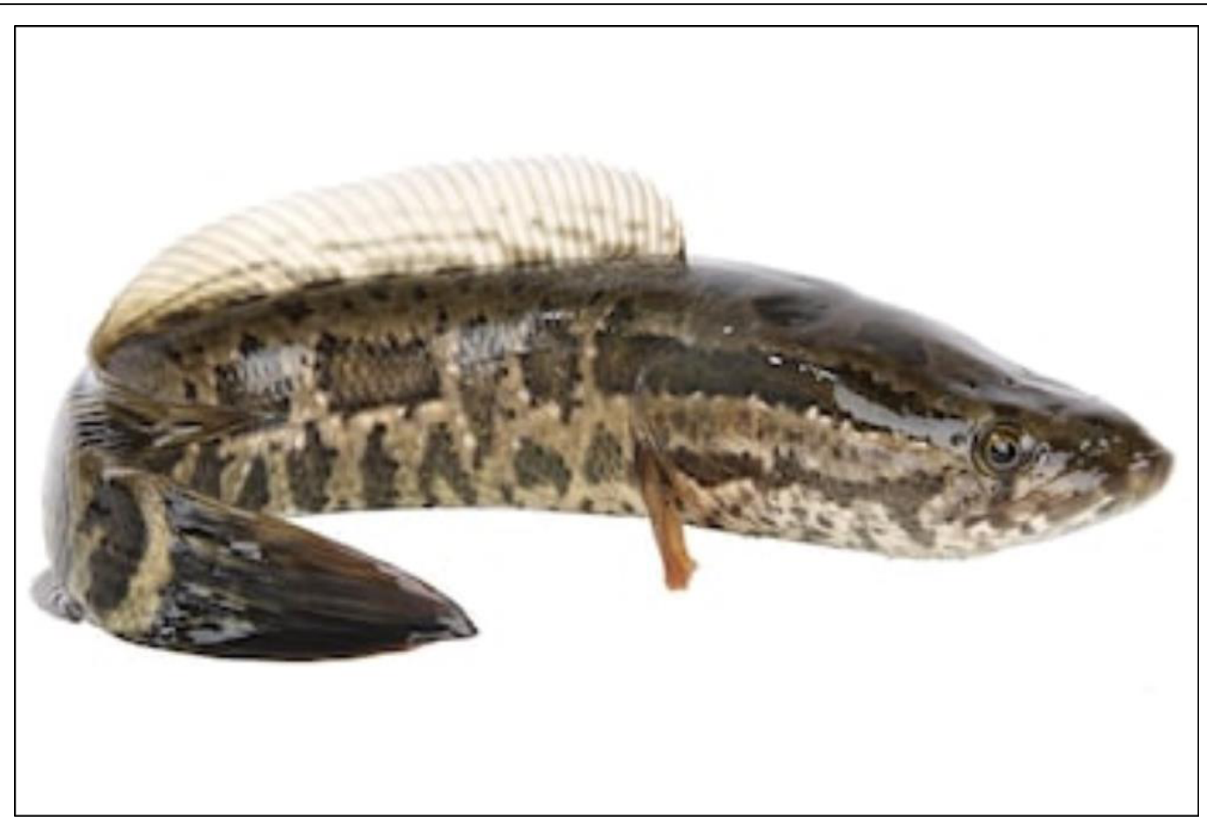

Fig. 5 Snakehead fish from the Channidae family. Snakehead range in size from 30-90 cm in length. Snakehead fish seasonally migrate from the main rivers and lakes into the flood plains during the rainy season. This makes them accessible to Cambodians living in areas away from the main waterways. Consequently, snakehead are both eaten fresh in the peak season and preserved for later use in the form of prohok sach

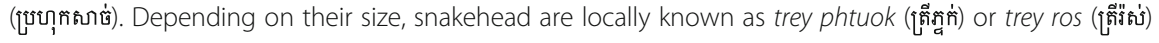

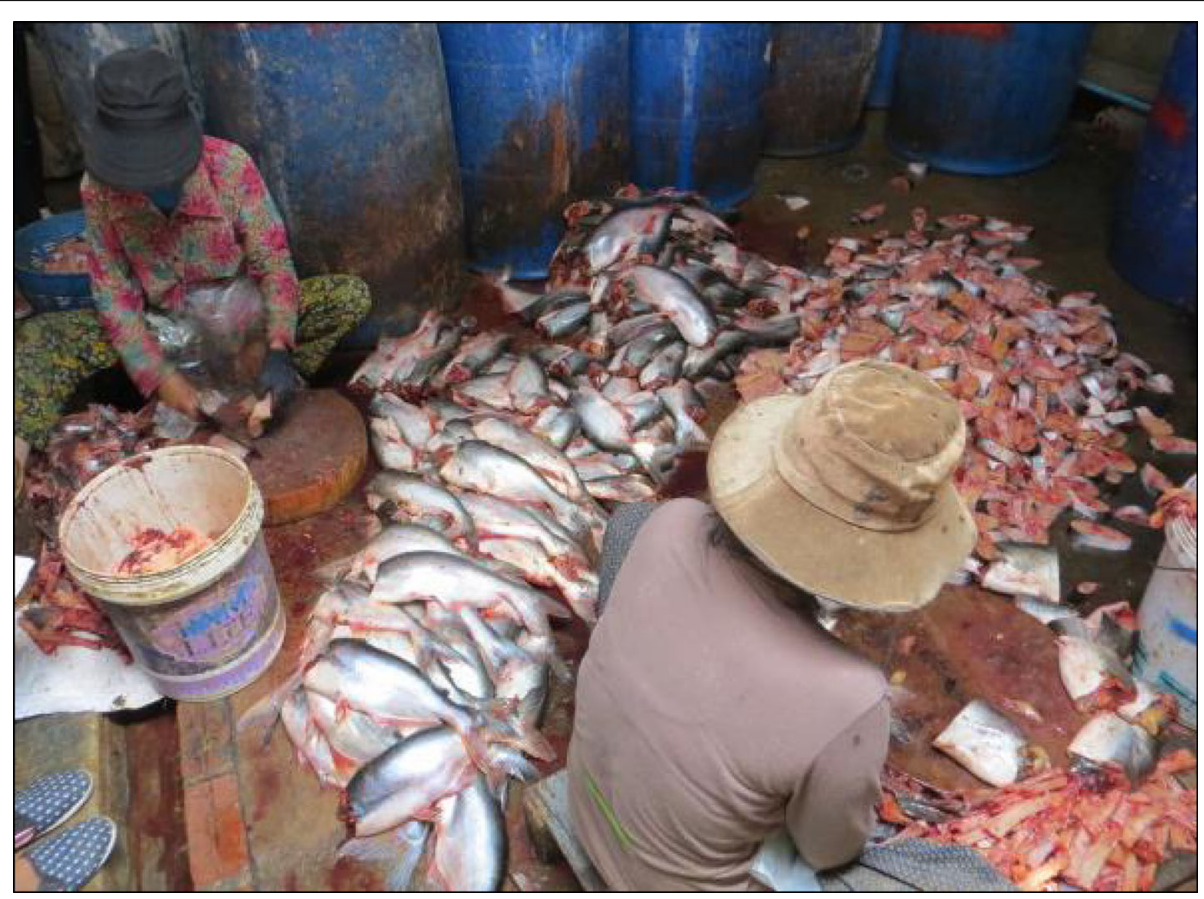

Fig. 6 Two fresh fish processors at a cooperative facility in Battambang Province. Fish preparation involves removing the heads, scales and internal organs (processor on the left). Then fresh fish are chopped into steaks (top right). Additional boneless pieces that result from processing are also reserved (bottom right). Separate batches of prohok are prepared that include either the bone-in or the boneless fish flesh. Photo credit Karen LeGrand 


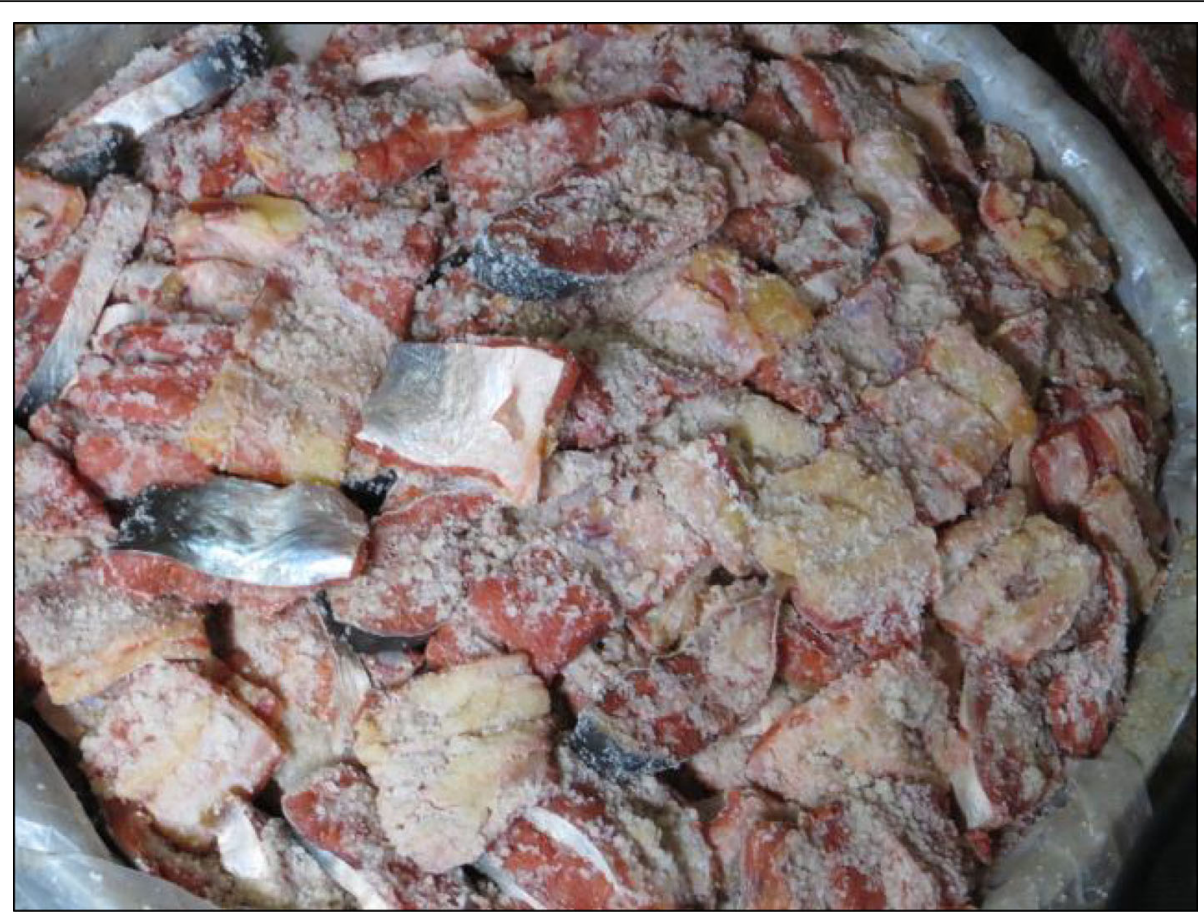

Fig. 7 Fresh fish prepared for first fermentation. After cleaning and chopping, fresh snakehead fish are placed into a container. Salt is added at 4$5 \%$ to coat the fish. The salt and fish are thoroughly mixed until the fresh fish are coated. The mixture is covered and left to soak overnight to initiate the early fermentation process. Photo credit Karen LeGrand

15-20\% salt to make prohok ch'oeung or 25-30\% salt to make prohok sach. To keep the fish from floating during the fermentation process, the fish are held down inside the container often with pieces of wood either propped under the rim or with rocks placed on top (Fig. 8a). Fermentation is conducted without air ventilation from stirring or shaking since exposure to oxygen causes a bad smell and granules to form which compromises the quality. The mixture is left to ferment in sealed plastic, earthenware, metal or concrete vats, or sometimes with a cloth tied over the mouth, for several months up to a year (Fig. 8b, c). Experienced fish processors test for doneness by evaluating the smell that emanates from the container when it is opened and pressing on the flesh of the fish to test its firmness. Another method is to remove a small portion of the meat and steam it in a bowl to more carefully evaluate the aroma and consistency of the fish. The final product that results from $100 \mathrm{~kg}$ fresh fish ranges from approximately $60 \mathrm{~kg}$ for prohok ch'oeung to approximately $40 \mathrm{~kg}$ for prohok sach.

These methods of fish preservation have originated from the empirical findings of local people over time. Experienced producers understand the effect of specific salt, equipment and duration of sun exposure and location of production on the quality and sensory characteristics of the final product. Therefore, over periods of many years, producers follow consistent techniques at a specific location to make prohok. Producers use ingredients of the same origin and produce largely standardized products to obtain characteristics that are unique to a given region or village. Some producers target specific flavor or appearance characteristics by adapting production methods to include or exclude the fish entrails or by moderating the use of additional ingredients such as ginger or galangal, roasted or fermented rice, or fruit like papaya or cucumber.

\section{Khmer culinary traditions: cooking with prohok}

Khmer cooks use prohok liberally to add depth of flavor to nearly every dish. Prohok is enjoyed in meals throughout the day and Khmer people attest that without its smell and flavor, food is not delicious.

Prohok has become such a common ingredient that the food just doesn't taste right without it.

“Interview, December 7, 2017"

Prohok is also used as a dipping sauce or simply mixed into a bowl of rice. Its powerful flavor is quite pungent and has been compared to the taste of old French cheese with a "fishy" smell. Cambodian culinary secrets have rarely been written down; the recipes have been handed down from mother to daughter and vary somewhat in 

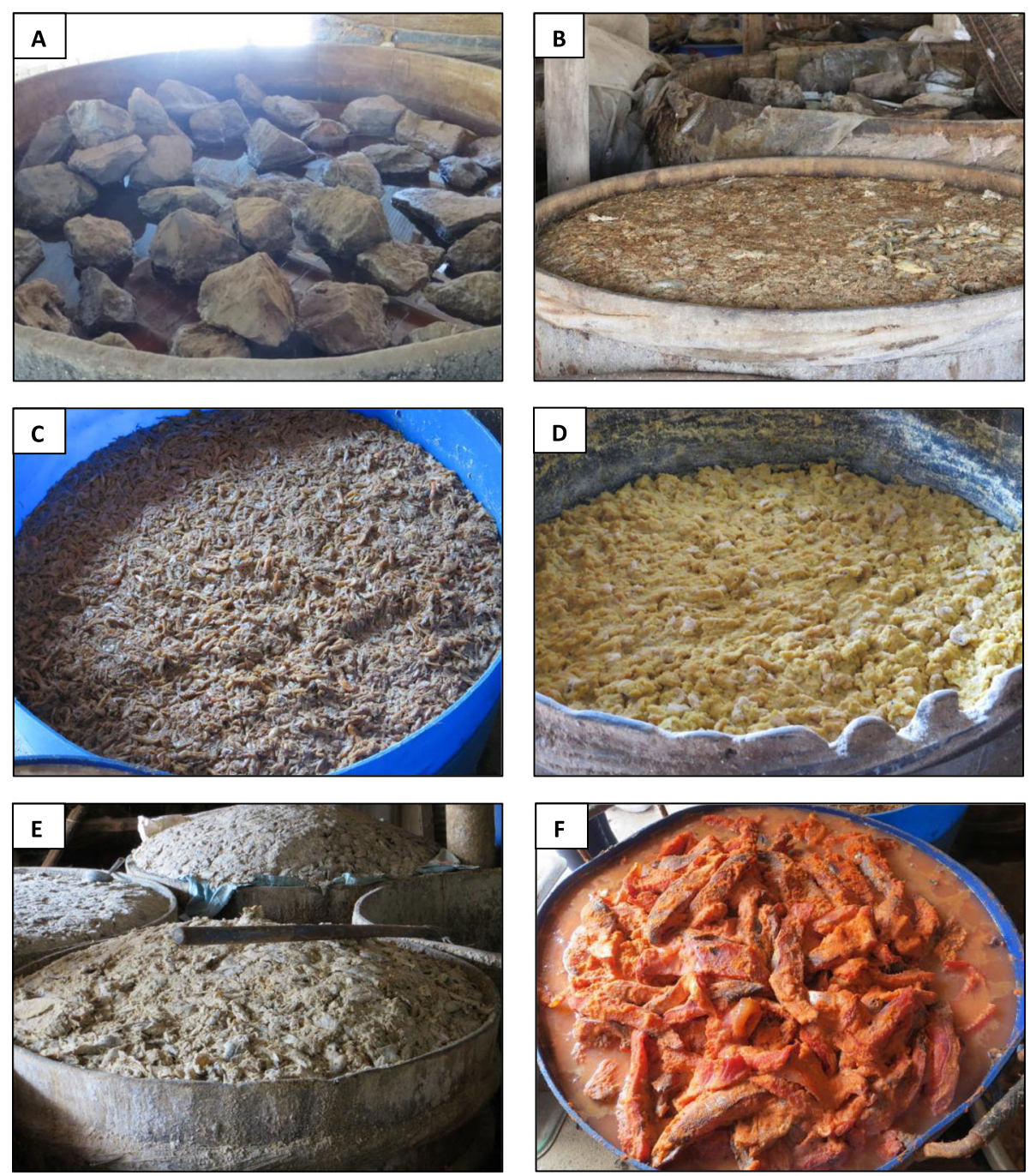

Fig. 8 Fish and salt are packed into containers of various types including earthenware and plastic. The lids are weighted down. The weights help to hold the fish in the liquid during the long fermentation process. Photo $\mathbf{a}$ and background of Photo $\mathbf{b}$ are containers with rocks on top of the lids as weights. Photo $\mathbf{b}$ foreground and Photos $\mathbf{c}-\mathbf{f}$ show various types of finished prohok in earthenware and plastic fermentation containers. Photo credit Karen LeGrand

different regions of the country. Ancient traditional cuisine blends prohok with other unique flavors and colors in ways that enhance the flavor and aroma of the individual ingredients. Cambodians have perfected the art of blending spices into pastes using ingredients including cloves, cinnamon, star anise, nutmeg, cardamom, ginger, and turmeric. They also blend other native ingredients with these spices including galangal, garlic, shallots, lemongrass, cilantro, kaffir lime leaves, and turmeric to make a distinctive and complex spice blend known as kroeung samlar

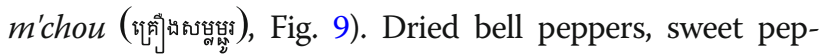
pers, and chilis are also used according to taste and to add color. The characteristics of a Cambodian cook's kroeung are distinctive and considered a measure of respect in Khmer culture. Kroeung and prohok blended together become a unique aromatic combination that is the most distinctive signature ingredient in the Khmer kitchen. These and other essential ingredients including tamarind, lemon grass, basil, sugar, and lime (commonly designated in Cambodia as lemon) flavor sauces, soups, stir-fries, and many other foods.

Cambodia's ubiquitous prohok is also found imbedded in culinary traditions throughout the region. Both Laos and the north-eastern region of Thailand were part of the Khmer Empire that dominated the area from 802 to $1431 \mathrm{AD}$, with some areas remaining occupied until the end of the $19^{\text {th }}$ century and into the early part of the $20^{\text {th }}$ century. Consequently, Khmer culture has greatly influenced regional traditions for millennia. It has been recorded that the centuries old Khmer practice of 


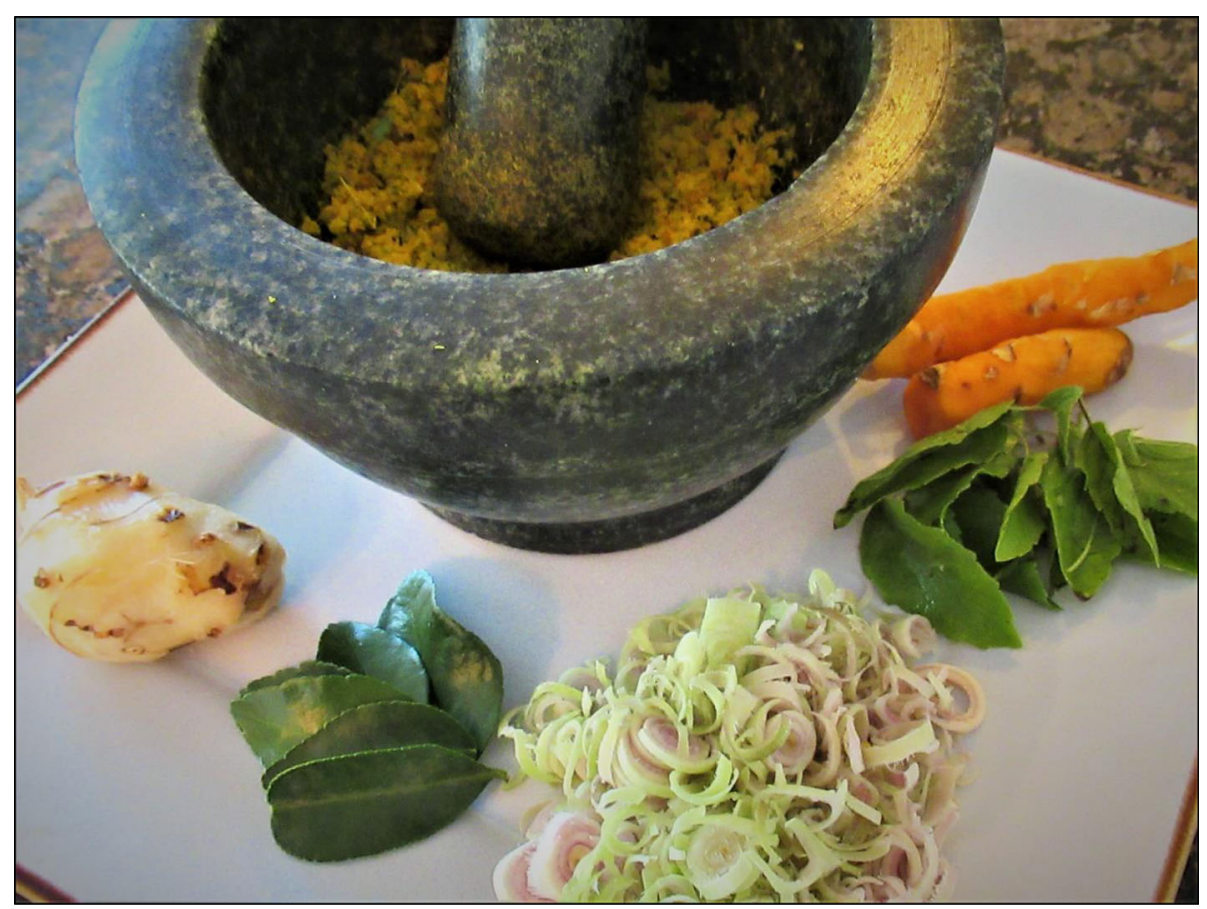

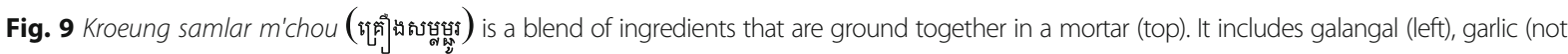
shown), shallots (not shown), lemongrass (bottom center), cilantro (not shown), kaffir lime leaves (green leaves), and turmeric (upper right). Mixed with prohok, it is the most distinctive blend of ingredients in a Khmer cook's kitchen. Food prepared by Thort and Muni Chuong. Photo credit Karen LeGrand

fermenting fish influenced chefs from Thai tribes as they migrated south and "borrowed" ingredients, including prohok, from Cambodia [32, 33]. A similar version of fermented fish is known in Thailand as pla raa.

\section{Cambodian main dishes}

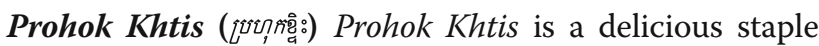
dish of Cambodian cuisine (Fig. 10). It is a dip made with prohok, kroeung samlar m'chou, minced pork belly, pea or cluster eggplants, garlic, tamarind, palm sugar, Kaffir lime leaves, chilis, and coconut milk. The prohok is fried with pork belly, which accentuates the flavor, particularly when high quality pork is used. This authentic Cambodian dip is served with fresh crispy vegetables that are sometimes wrapped together in cabbage or other large leafy vegetables for dipping.

Prohok Kab (๒บบฺุnกษ่) Prohok kab is a very popular food in the countryside of Cambodia (Fig. 11). It is commonly consumed several times per week with fresh vegetables and rice, particularly by farmers. Prohok kab is an inexpensive, convenient meal that is easily transported away from home and retains its quality during long days spent tending rice fields and animals. This main dish is a delicious combination of prohok, roasted ground pork, mushrooms, and young leafy tamarind with spices ground into the mixture including lemon grass, basil, turmeric, and galangal. Another key ingredient is small fish which are ground in with sugar, salt, and basil to taste. The thick mixture is packed and wrapped in young banana leaves, then roasted for $20 \mathrm{~min}$ on an open flame to give it a pleasant char flavor. It can be preserved for several days in banana leaves at room temperature. It is most often eaten with rice and sometimes fresh produce including cucumber, yard long bean, green mango, or other items that can be foraged from the fields or forest.

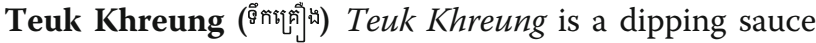
made with prohok, fresh fish, and a variety of spices that is commonly eaten for lunch or dinner with vegetables and rice (Fig. 12). To make teuk khreung, the prohok is steamed with a little water and filtered to remove the bones. Boiled, deboned fresh fish is added along with tamarind, sugar, garlic, and shallots. Cooked vegetables, garlic, and chili are ground and added to the fish mixture. This thick sauce is eaten with raw vegetables including cabbage, morning glory, and cucumber.

Prohok sauce with BBQ beef Another favorite prohokbased sauce is served with barbecued beef and fresh vegetables (Fig. 13). This dish is described as juicy and is especially appreciated because beef is not commonly consumed in Cambodia. The sauce combines a pleasant aroma with sweet, sour, and spicy flavors derived from a delicious combination of prohok ground with garlic, sugar, and 

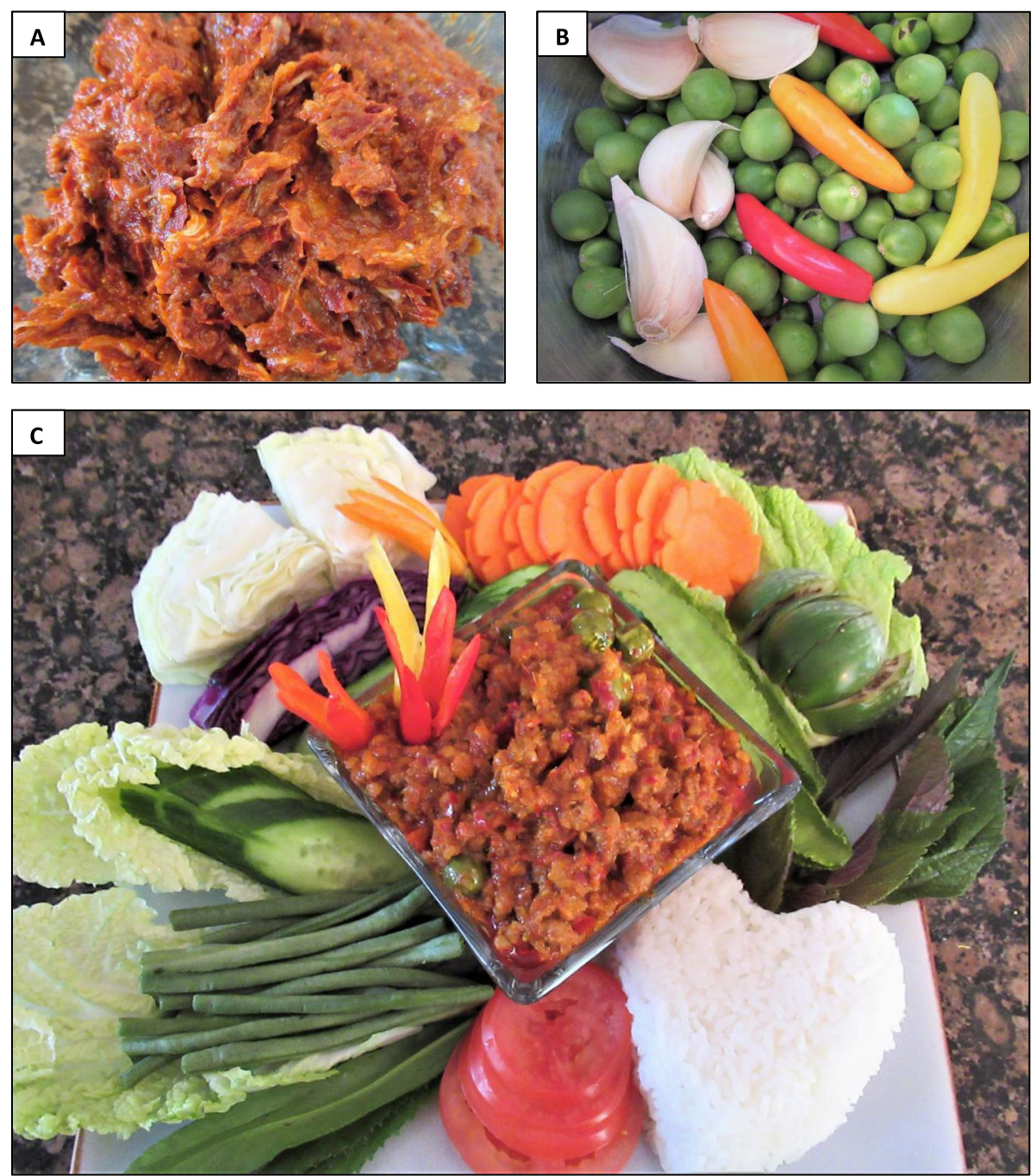

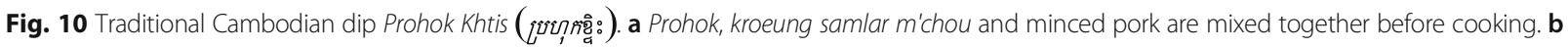
Pea eggplants, garlic, and chilis are cooked separately. c Prohok Khtis is a hearty and delicious savory dip with a hint of sweetness from palm sugar and coconut milk. Served with fresh dipping, vegetables, and rice. Food prepared by Thort and Muni Chuong. Photo credit Karen LeGrand

lime. Lemon grass, peanuts, and chilis are also added to taste. The sauce is served with barbecued beef cooked medium rare, fresh green tomato, cucumber, carrot, cabbage, other vegetables, and lime. Diners commonly wrap the ingredients together inside the cabbage leaves to dip in the prohok sauce.

\section{Cambodian soups or stews and side dishes}

A meal in Cambodia is not complete unless it includes some type of soup, known as sngowr (โถูก), or stew, known as sam$\operatorname{lar}($ ถั่ $)$.

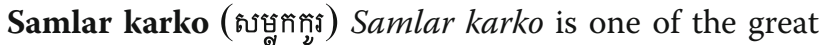
fusions of traditional ingredients combined together into a soup commonly served with many meals throughout the week (Fig. 14). This soup is made by mixing prohok together with a variety of spices into a paste made up of lemon grass, garlic, and a variety of roots that are related yet exhibit unique flavors. These include two different types of turmeric, blue ginger, Thai ginger, galingale, Thai galangal, finger root or Chinese ginger (scientific name Boesenbergia rotunda, known in Khmer as kcheay [ฆ్心 entific name Alpinia galanga, known in Khmer as romdeng

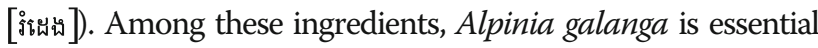
and without it a Cambodian diner would consider the taste of samlar karko to be very strange. This soup is enjoyed year-round and includes seasonally available fresh fish, vegetables, and fruit. In jackfruit season, the peel from around segments of jackfruit are also included. After cooking all these ingredients together, roasted rice is added with water to make the soup's characteristic samlar consistency. 

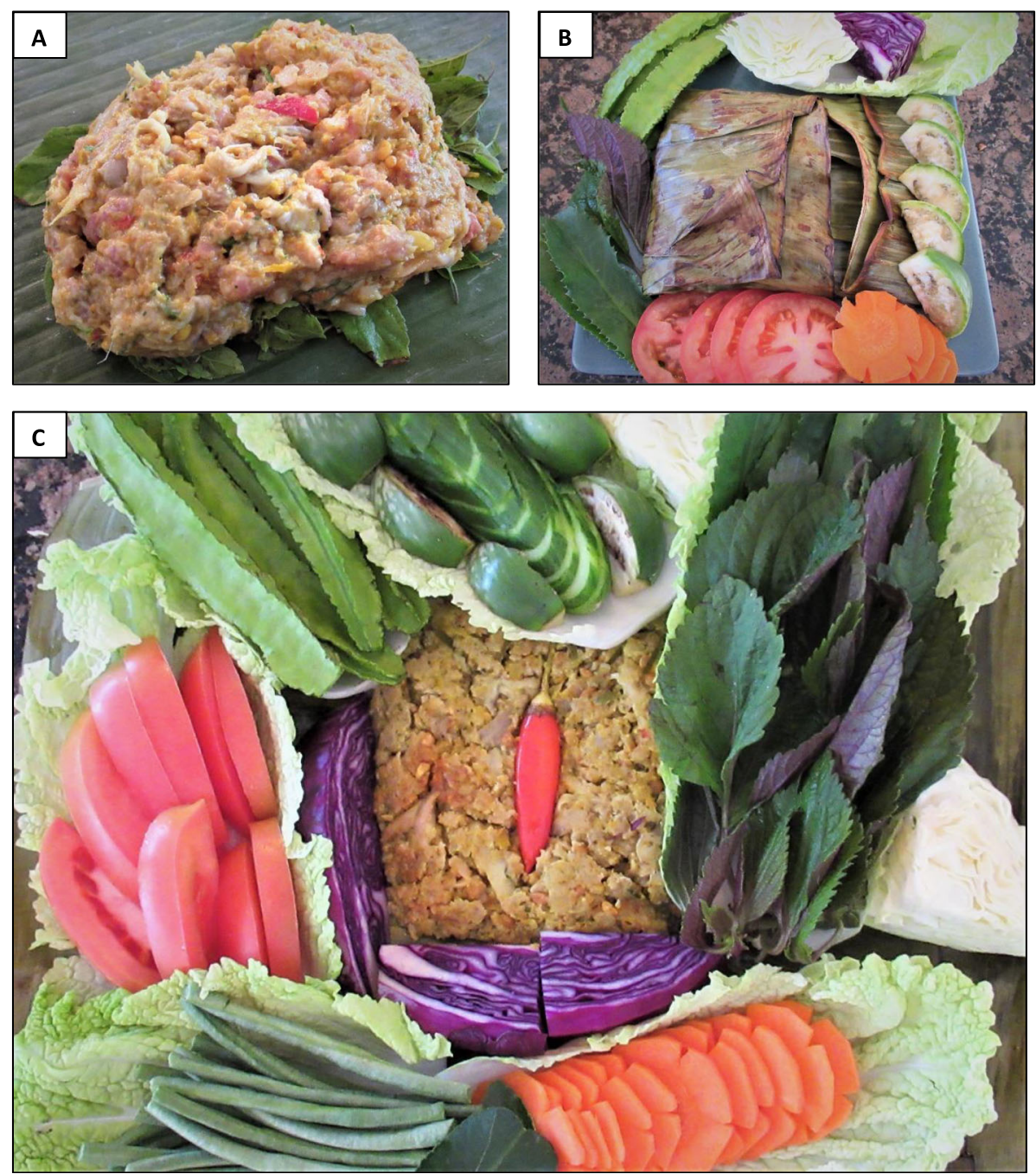

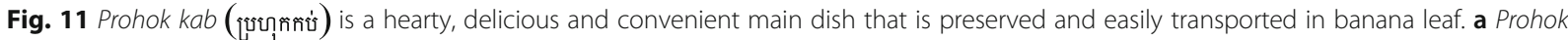
mixed with mushrooms, ground pork, a variety of spices, and some chili is sometimes placed on a bed of basil before being wrapped in a banana leaf. $\mathbf{b}$ The packed banana leaf is roasted over an open flame until slightly charred. c Prohok kab (center with chili on top) can easily be transported in the banana leaf and eaten on the go with fresh vegetables. Food prepared by Thort and Muni Chuong. Photo credit, Karen LeGrand

Khmer noodle with samlar prahir (๘ษษนีที่) Samlar prahir is a classic noodle soup commonly eaten for breakfast and made with both prohok and fresh fish (Fig. 15). This dish is made by first boiling fresh fish and removing the bones. The cooked fish is then ground with lemon grass, lime, garlic, turmeric, and galangal. The mixture is then added to boiling water along with prohok. Dried prawns and peanuts are ground together and added to the mixture along with coconut cream. These ingredients are cooked together and poured over noodles immediately before serving. Diners add desired vegetables including cucumber, banana flower, mung bean, bean sprouts, water spinach, river tamarind, and mint as they enjoy the meal.
Neem tree salad with prohok dressing Neem tree (sometimes referred to as Nimtree) salad is a seasonal dish normally prepared during the rainy season in Cambodia when the Neem tree has tender shoots and flowers (Fig. 16). Neem tree leaves, flowers, and seeds have been valued for centuries for their medicinal properties and Neem tree salad is considered to be good for health. The somewhat bitter taste and pleasant aroma stimulates a good and healthy feeling among diners. This dish is prepared by chopping Neem tree leaves and flowers with other ingredients including cucumber, cabbage, banana flower, carrot, garlic, and red garlic. These and sometimes additional vegetables are mixed together with smoked fish and cooked pork or tiny dried shrimp. Prohok dressing is prepared by 

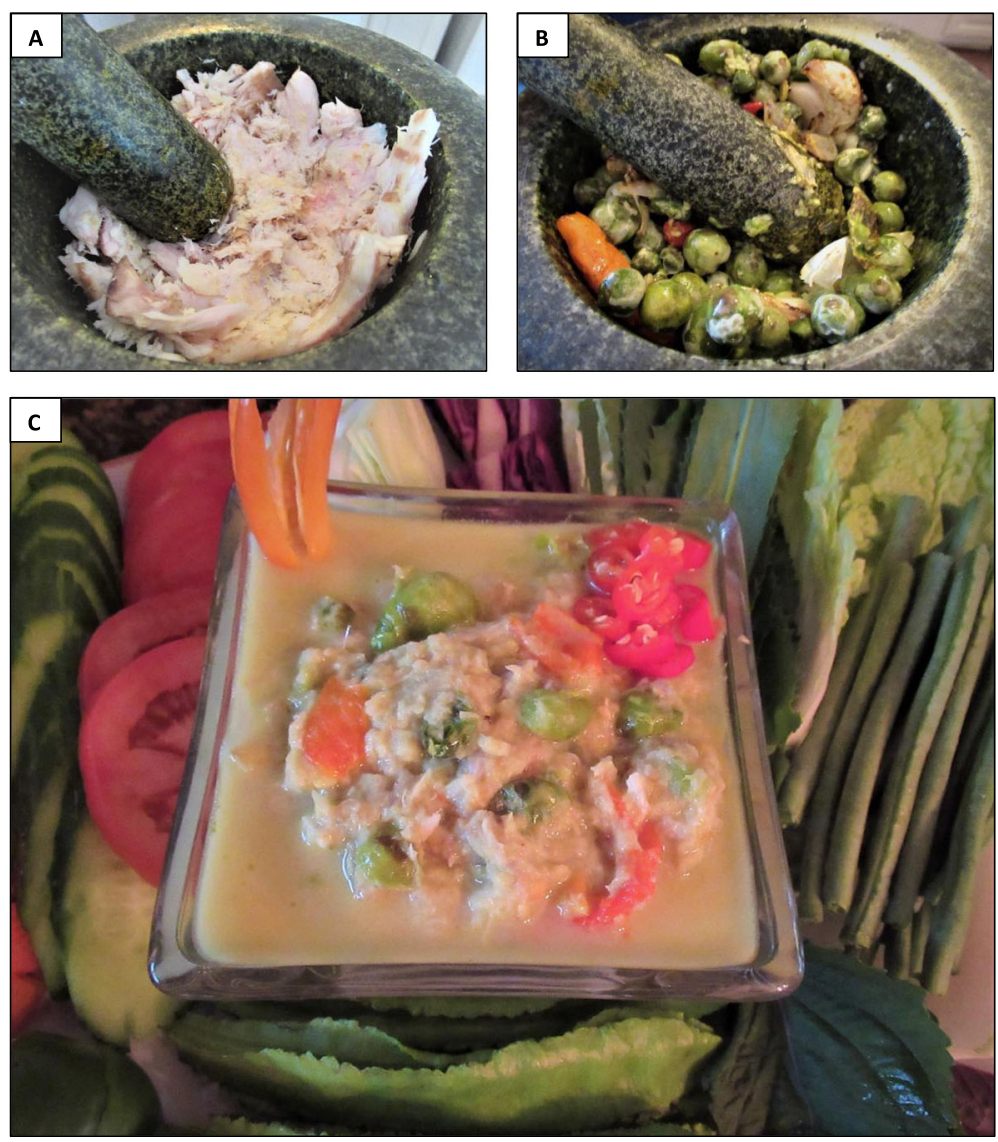

Fig. 12 Teuk Khreung ( deboned. $\mathbf{b}$ Cooked pea eggplants, garlic, and chili are ground and added to the fish mixture. $\mathbf{c}$ This thick dip is served with a variety of fresh vegetables. Popular vegetable choices include cabbage, green bean, tomato, and cucumber. Food prepared by Thort and Muni Chuong. Photo credit Karen LeGrand

adding boiling water to prohok, stirring and filtering the mixture through a bamboo sieve to remove the bones of the fish. The resulting "prohok water" is mixed with sugar, fish sauce, and tamarind to taste. This dressing is tossed into the salad which is garnished with a sprinkle of peanuts and mint to taste.

\section{Microbiology and chemistry}

Limited information is available about the biological, chemical, and enzymatic processes involved in fish fermentation since only a small number of studies have been conducted. Of the research reported thus far, publications are scarcely known outside Asia [2, 3, 29]. However, the significance of some important processes in the fermentation of prohok can be inferred from these studies and general scientific principles.

Since salt is one of the only two main ingredients in prohok, it is not surprising it contributes in various ways to the fermentation process. For example, one of the key roles of salt is to inhibit pathogenic and putrefactive microorganisms. Compounds that are also capable of inhibiting microbes, such as organic acids, are produced during fermentation; however, this mechanism is unlikely to significantly contribute to microbial inhibition. The $\mathrm{pH}$ ranges observed in fish fermentations do not allow the organic acids to be sufficiently protonated to diffuse across the plasma membrane of microbial cells $[34,35]$. Other illustrations of the role salt plays in fish fermentations are exemplified in some of the sensory characteristics of the final products. The presence of even very low concentrations of calcium and magnesium salts differentially affect the taste and texture of the final product in ways that can be readily detected by experienced fish processors [29]. Consequently, the specific origin and quality of salt used in the fermentation is highly important to the outcome of the final product. This is one of the primary reasons fish processors strive to use consistent sources of salt. Another factor fish processors are acutely attune to is the property of salt to attract and hold water molecules, which affects not only the taste but also the texture of the final product. Experienced processors understand empirically how 


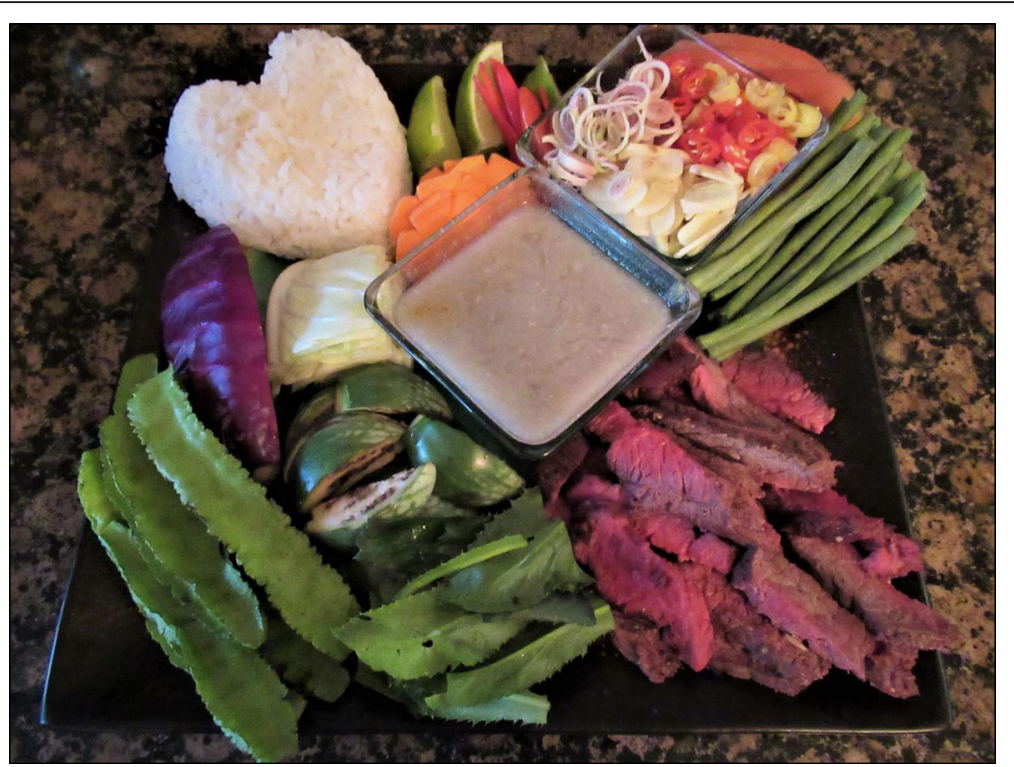

Fig. 13 Traditional Cambodian dip of prohok made into a sauce (square bowl in the center). Additional chopped garlic, chilis, and lemongrass are often served separately and added to taste (square bowl at top right). This meal is considered a special treat that is served with beef barbecued rare (bottom right). A variety of fresh vegetables including carrot, cabbage, eggplant, and green bean add a crisp texture to each bite. Often rice is served as an accompaniment (top left). Food prepared by Thort and Muni Chuong. Photo credit Karen LeGrand

slightly different concentrations of salt affect the final product and will adjust the salt content at different stages of production to manipulate the texture of their own unique preparation of prohok.

While most microbes are not able to grow at the concentrations of salt added to make prohok, halophilic microbes that thrive in high salt conditions and halotolerant microbes that are capable of growing in high salt conditions do influence the quality of the final product. Halophiles and halotolerant microbes can come from the fish viscera and gills or are introduced with the salt, which is generally very impure and contains many halophilic microorganisms. Although the role of halophilic and halotolerant microorganisms during fermentation and their effect on the final product is not clearly understood, it is likely they do have impact. Studies show that their numbers initially increase rapidly in the brine, are sustained throughout production, and are even higher in the final product [35-39].

While some studies have been conducted to determine the chemical and microbial composition of various fermented fish products in Southeast Asia, the first detailed analysis of the chemical and microbial properties of Cambodian prohok was conducted in 2014 [35]. Analysis of the fermentation process was done at day 20 and again after 1 and 3 months. Chuon et.al. determined the amino acid composition and found that of the dominant amino acids, three were essential amino acids that must be obtained through diet (valine, leucine, and lysine). The study also identified the types of acid present and determined the highest concentration was acetic acid, suggesting acetic acid bacteria are present and largely responsible for the pungent, sometimes sour flavor. Also, considerable amounts of lactic acid were found, which suggests lactic acid bacteria also contribute to the smell, taste, texture, and color of prohok. No citric acid was found, indicating citric acid-producing microorganisms are likely not involved in the fermentation process. The study also included some microbial analyses. Overall, bacterial counts were found to range from $10^{5}-10^{7} \mathrm{cfu}$ $\mathrm{g}^{-1}$ and consisted primarily of Gram-positive cocci or rods. Among these bacteria, halophilic and halotolerant bacteria Staphylococcus and Tetragenococcus were primary (estimated at $\left.10^{5}-10^{6} \mathrm{cfu} \mathrm{g}^{-1}\right)$. Clostridium was also a major genus observed $\left(10^{5} \mathrm{cfu}^{-1}\right)$. Occasionally, aerobic spore-forming bacilli including Bacillus, Virgibacillus, Halobacillus, and Lysinibacillus were found $\left(10^{2}-\right.$ $\left.10^{5} \mathrm{cfu}^{-1}\right)$. A minor constituent detected only in prohok fermented for one month was the Gram-negative genus Psychrobacter. Compared to bacteria, viable fungi were relatively low $\left(10^{2} \mathrm{cfu} \mathrm{g}^{-1}\right)$ and found only in fermented products after one month (Rhodotorula) and after three months (Candida).

The information gained from this study about the chemical and microbial composition of prohok provides some scientific insight into the fermentation process. Clostridium and Tetragenococcus were found at all stages of fermentation and may play significant roles throughout production [35]. Specifically, some members of the Clostridium genus are regarded as strong producers of acetic acid and the genus also reportedly has 

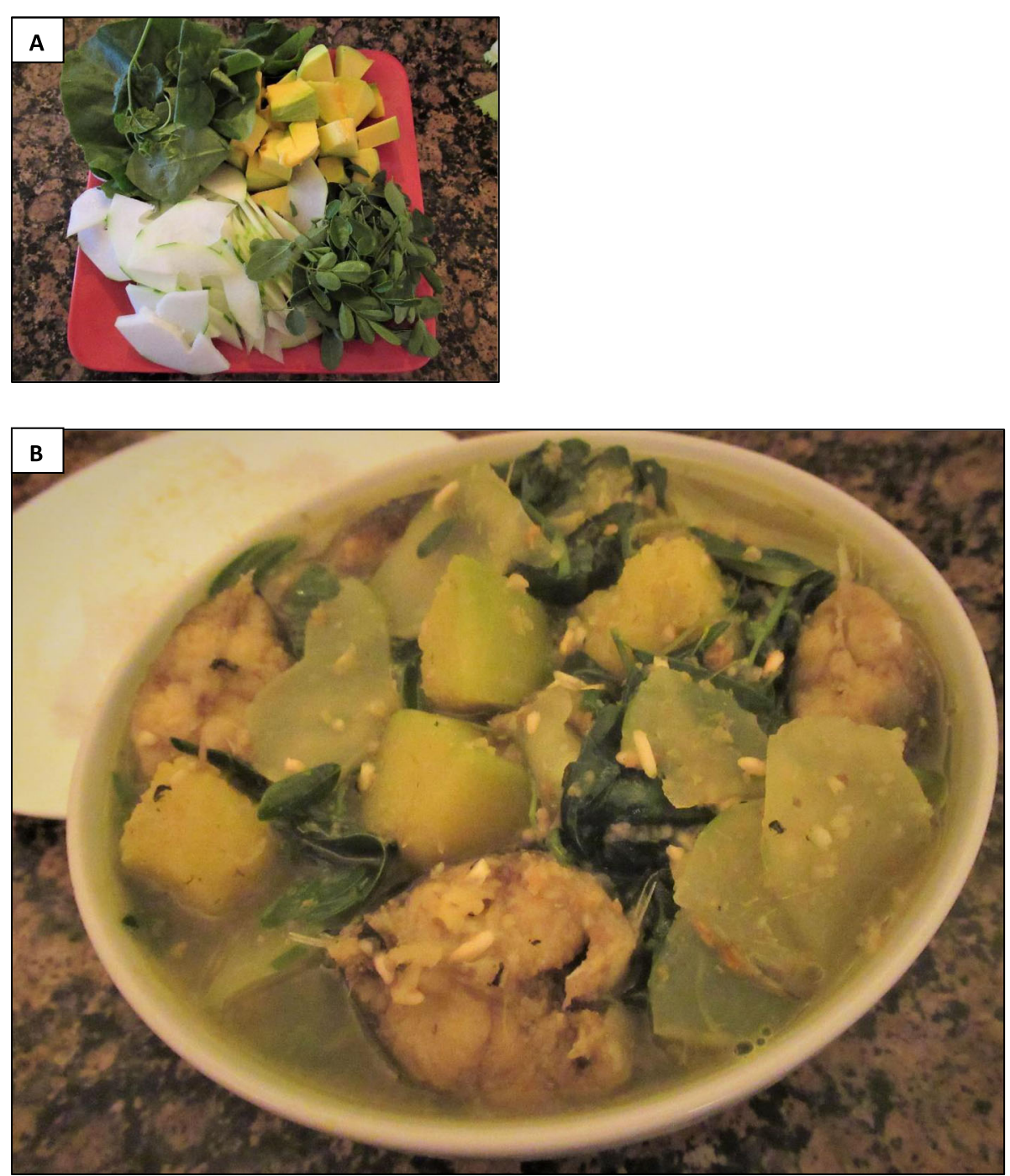

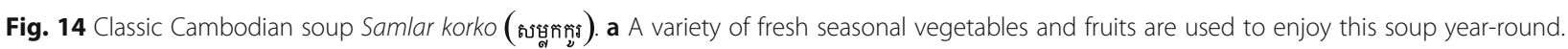
Shown are immature mango, immature papaya, and moringa. $\boldsymbol{b}$ Prohok blended with a variety of spices forms the base for this soup. Cooked fresh fish and other traditional ingredients depend on the seasonal varieties available. Roasted rice is added to the mixture and cooked just before serving to give the soup its characteristic thick consistency. Food prepared by Thort and Muni Chuong. Photo credit Karen LeGrand

strong proteolytic enzymes [40, 41]. It is possible Clostridium may be the primary acetic acid producers and produce enzymes that help hydrolyze the fish muscle during fermentation. Tetragenococcus are known from other studies to be major lactic acid producers in highsalt-containing fermented foods such as fish sauce and soy sauce [42-45]. It is possible they may be the primary producers of the lactic acid found in Chuon's study. In general, the importance of Tetragenococcus in fermentation processes is evident because several different isolates have been used as starter cultures to process other fermented fish and food products [44, 46-54]. Further studies of prohok may be directed at determining whether Tetragenococcus may be useful as a starter culture for prohok.
Additionally, Staphylococcus were found at high concentrations and may play an important role since members of this genus are known to produce proteolytic and lipolytic enzymes [55-57]. It is possible Staphylococci contribute proteolytic enzymes that degrade the fish muscle and lipolytic enzymes that hydrolyze some fat. However, it is unlikely Staphylococci are solely responsible for breaking down fat since Chuon et.al. showed that elimination of the fish entrails significantly lowered the fat content from approximately $15 \%$ to $0.0017-0.0107 \%$. This suggests microbial-derived lipolytic enzymes are not the only contributors to digesting fat, and that fish enzymes from the fish gut are also responsible for breaking down fat during fermentation. 


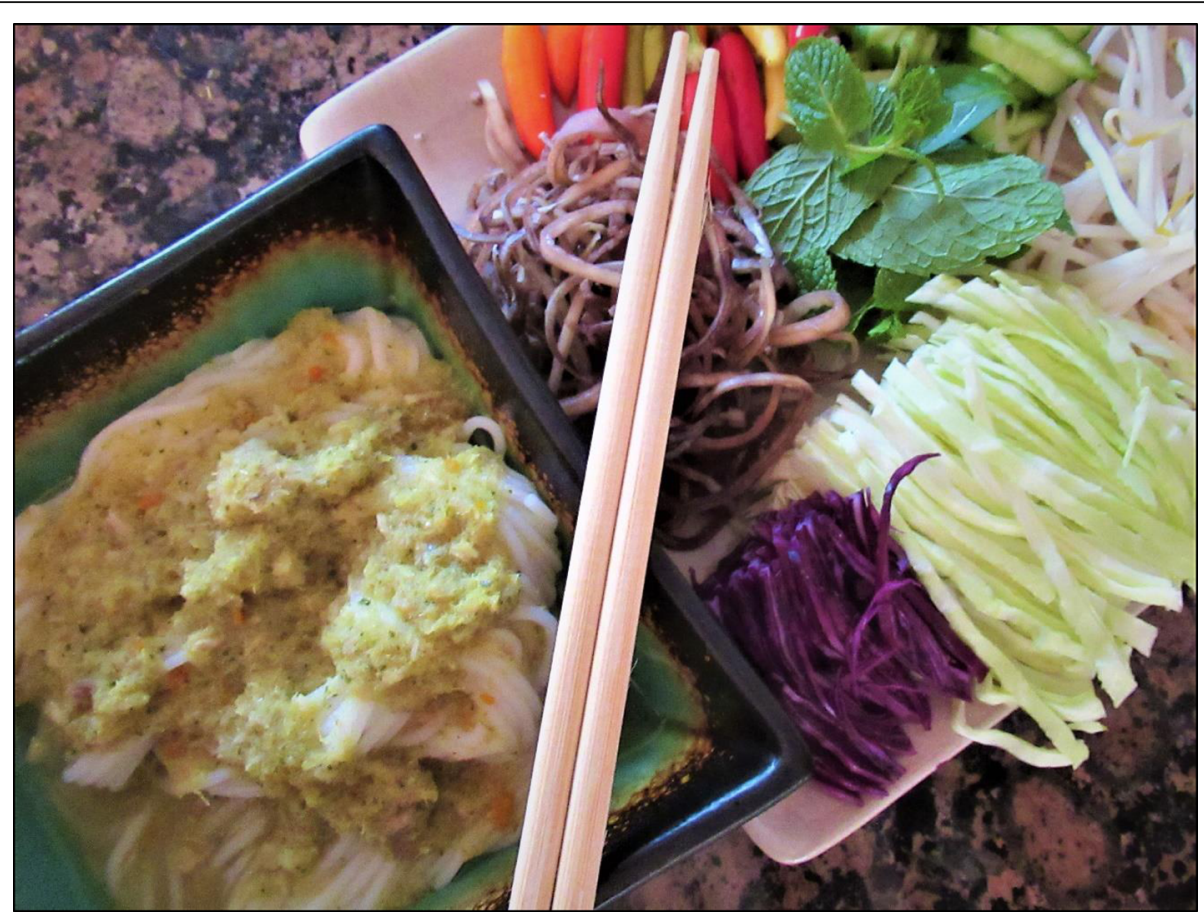

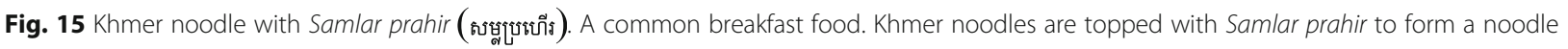
soup (bottom left). A variety of fresh vegetables including banana flower, cabbage, cucumber, and bean sprouts are added just before each bite. Food Prepared by Thort and Muni Chuong. Photo credit Karen LeGrand

\section{Commercialization of prohok}

Official production records indicate that in 2013, more than 15,000 tons of prohok was produced in eight Cambodian provinces (Siem Reap, 3,825 tons; Battambang, 2,887 tons; Kampong Chhang, 2,600 tons; Pursat, 2,087 tons; Phnom Penh, 1,790 tons; Prey Veng, 1,620 tons; Takeo, 186 tons; Kratie, 36 tons).This includes production at some larger scale modern processing facilities that supply both domestic and export markets. The majority of traditionally processed prohok, however, is made by small- and medium-scale producers for domestic consumption [7, 11]. Most of the urban supply of prohok is purchased directly from individual producers and few wholesalers exist [11, 58]. Annual commercial production is likely even higher than official records indicate since most fish processed throughout the country is at the hand of small, family-scale producers who make between 15 and $20 \mathrm{~kg}$ of prohok per day in the peak season. A noteworthy amount of prohok is made by fishing households themselves and other people who buy fish to make prohok for their own consumption.

Many of the small/family-, medium-, and modern/industrial-scale prohok producers are located in the provinces that surround the Great Lake, which are Siem Reap, Battambang, Kampong Chhang, and Pursat. Some individual producers in Siem Reap and Battambang Provinces have organized themselves into cooperatives to help streamline production. One advantage of these cooperative facilities is that they offer a centralized location for fishermen to deliver fresh fish to small- and mid-scale processors. Another aggregating facility is a wholesale fish market, Prek

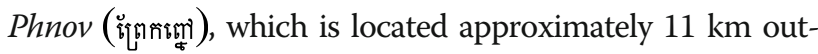
side the capital city of Phnom Penh on the Tonle Sap River. In recent years, approximately 12,500 tons of fish have been traded through Prek Phnov to small- and mid-scale producers in regions of the country away from the Great Lake [59].

\section{Optimization}

The extent to which traditionally produced prohok continues to be highly valued by Khmer families is remarkable. While modernization continues in Cambodia and other cultural and family traditions are being replaced, the practice of prohok production remains largely unyielding to change. Overall, food preparation technology is advancing and moving towards larger-scale manufacturing. Yet small-scale production of prohok and a wide variety of fresh vegetables to accompany Khmer people's favorite dishes continue to dominate consumer demand. Amidst one of the highest rates of urbanization in the world, Cambodian people are increasingly being drawn away from functions around the home. While this results in less time to devote to food preparation, it is remarkable that Khmer people prefer to make their own 

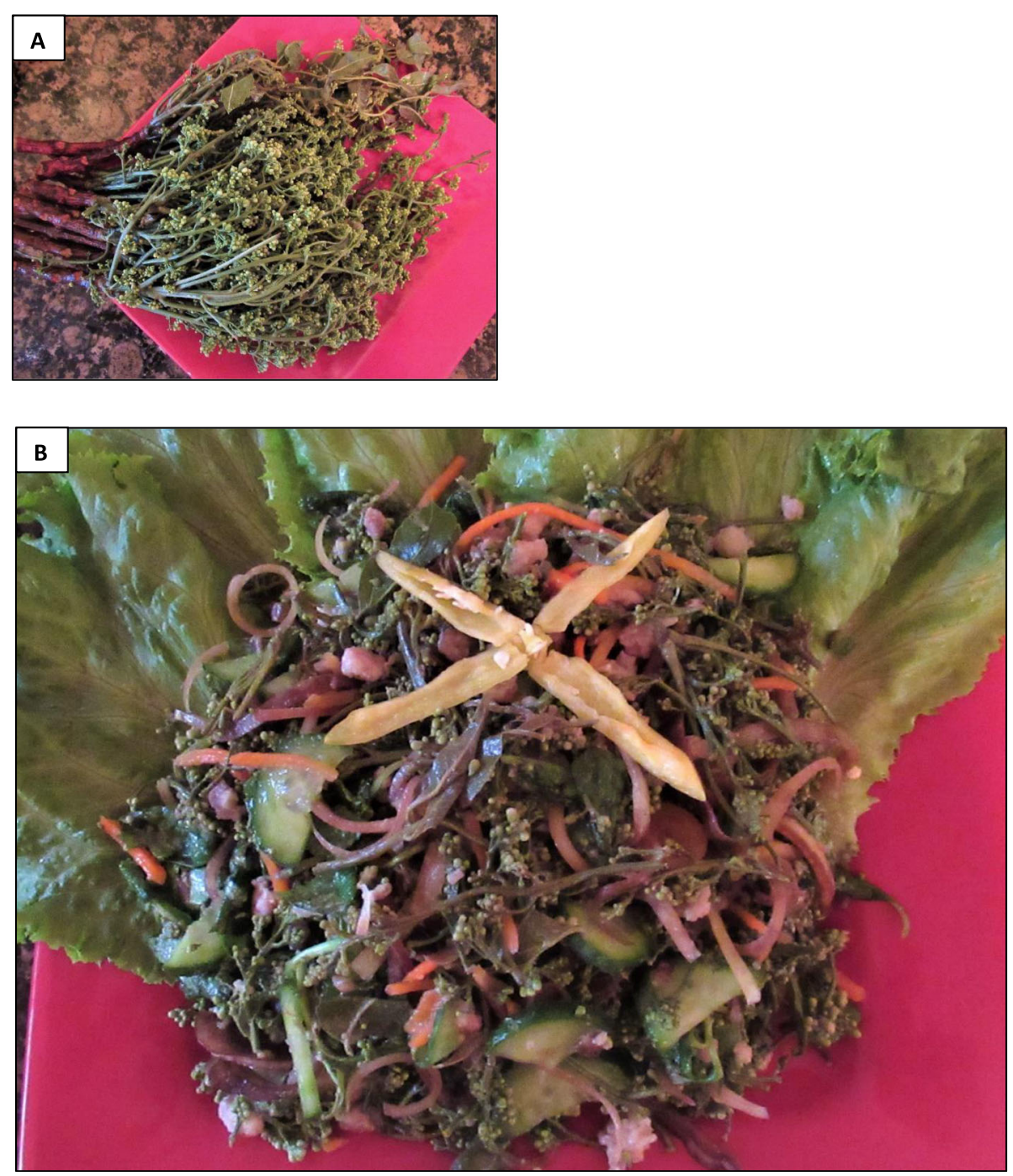

Fig. 16 Neem tree salad with prohok dressing. A seasonal dish prepared with greens considered to have medicinal properties. They originate from the neem tree which is considered overall be good for promoting health. a The tender shoots and flowers of the Neem tree are readily available in the rainy season. $\mathbf{b}$ Prohok dressing is tossed together with the Neem tree. Other vegetables are also included in this healthy side dish. These include carrot, cucumber, and banana flower. Food prepared by Thort and Muni Chuong. Photo credit Karen LeGrand

prohok rather than purchase from large manufacturers. Cambodians continue to seek the nuanced flavors, textures, and aromas they have valued for generations and desire high-quality fresh vegetables over the many types of processed foods now available. As modernization influences tradition, age-old fish preservation methodologies continue to be essential to Cambodian people. These perceptions of Cambodian people and the value placed on traditional preparations of prohok are important considerations when looking at potential ways to optimize production.

\section{Conclusion}

The historic traditions of fish preservation and the cuisine in which it is used remain an integral part of Cambodian society and Khmer culture today. The palate of the Khmer people is so refined they are able to distinguish between many different regional preparations, grades, and qualities of prohok. The different tastes, textures, and aromas are influenced by multiple factors including the method of preservation; different types of additional ingredients such as herbs, fruits, or vegetables; the kinds of microorganisms present during the fermentation; the nutritional status of the fish; the origin of the salt; the types of salt impurities present; and even the surrounding air in the production environment. The empirical knowledge of traditional practitioners and experienced fish dealers about how to manipulate each of these factors to develop specific sensory characteristics is integral to Khmer cultural. Additional scientific studies are needed to further investigate prohok fermentations and better understand 
the contributions of each of these factors to the unique flavors produced by traditional practitioners and beloved by Khmer people.

\section{Abbreviation}

cfu $\mathrm{g}^{-1}$ : colony forming units per gram (a representation of the number of bacteria present in one gram of sample)

\section{Acknowledgements}

The authors are grateful for the contributions of others to this study including Gnean Nak Da, Thort Chuong, Muni Chuong, Netra Buntong, and Sean Kiely. Many thanks to the General Department of Fisheries of the Kingdom of Cambodia and the Cambodian people who were eager to share insights into their culture, family traditions, and passion for food.

\section{Authors' contributions}

Each author made substantial contributions to conception and design. KL and $\mathrm{BB}$ were responsible for field site visits, acquisition of data, analysis, and interpretation of data. GMY provided critical feedback on presentation of the data. KL drafted the manuscript. BB and GMY critically revised the manuscript for important intellectual content. All authors read and approved the final manuscript.

\section{Authors' information}

KL and GMY are international food safety microbiologists and food value chain experts who have worked in Asia and Southeast Asia for more than 8 and 15 years, respectively. BB, a postharvest and food value chain expert, is the Director of the Division of Research and Extension at the Royal University of Agriculture and responsible for a wide variety of food and agriculture related research throughout Cambodia.

\section{Funding}

This work was supported by awards to KL from the University of California President's and Chancellor's Postdoctoral Fellowship Program and the United States Agency for International Development Borlaug Global Food Security Graduate Research Program, grant no. 13076416, as part of the U.S. government's global hunger and food security initiative called Feed the Future. It was also made possible in part by a subaward to KL from the United States Agency for International Development Feed the Future Innovation Lab for Collaborative Research on Horticulture, subaward no. 09002945-130.

\section{Availability of data and materials}

All data generated or analyzed during this study are included in this published article.

\section{Competing interests}

The authors declare that they have no competing interests.

\section{Author details}

'University of California, Davis, College of Agricultural and Environmental Sciences, One Shields Way, Davis, CA 95616, USA. ${ }^{2}$ Royal University of Agriculture, Division of Research and Extension, Dangkor District, PO Box 2696, Phnom Penh, Cambodia. ${ }^{3}$ Sierra College, Sciences and Mathematics, Biological Sciences Department, 5100 Sierra College Blvd., Rocklin, CA 95677, USA.

\section{Received: 29 December 2018 Accepted: 30 October 2019}

Published online: 06 May 2020

\section{References}

1. Kwon DY. Why data creation is important for ethnic foods. J Ethnic Foods. 2017:4(4):211-2.

2. Tamang JP, Holzapfel WH, Watanabe K. Review: diversity of microorganisms in global fermented foods and beverages. Front Microbiol. 2016. https://doi. org/10.3389/fmicb.2016.00377.

3. Thapa N, Pal J, Tamang JP. Microbial diversity in ngari, hentak and tungtap, fermented fish products of Northeast India. World J Microbiol Biotechnol. 2004;20(6):599-607.

4. Campbell-Platt G. Fermented foods - a world perspective. Food Res Int. 1994;27(3):253-7.
5. Kingdom of Cambodia National Institute of Statistics and Directorate General for Health. Cambodia demographic and health survey 2000. Phnom Penh: The Institute; 2001. [cited 2019 October 11]. Available from: https:// dhsprogram.com/pubs/pdf/FR124/FR124.pdf.

6. Asian Society. The Cambodian diaspora: community building in America. Hong Kong: The Society; 2018. [cited 2019 Oct 11]. Available from: https:// asiasociety.org/cambodian-diaspora.

7. Kingdom of Cambodia Ministry of Agriculture, Forestry and Fisheries. The strategic planning framework for fisheries: 2010-2019: fishing for the future. Phnom Penh: The Ministry; 2011. [cited 2018 Nov 1]. Available from: http:// extwprlegs1.fao.org/docs/pdf/cam143042.pdf

8. Mekong River Comission. Consumption and the yield of fish and other aquatic animals from the lower Mekong Basin. Vientiane: The Commission; 2007. [cited 2018 Nov 1]. 87 p. Available from http://www.mrcmekong.org/ assets/Publications/technical/tech-No16-consumption-n-yield-of-fish.pdf.

9. Mousset E, Rogers V, Saray S, Ouch K, Srey S, Mith S, et al. Role and value of fish in the welfare of rural communities in Cambodia [Welfare data analysis] Phnom Penh: WorldFish Center and Inland Fisheries Research and Development Institute, Fisheries Administration; 2016. [cited 2019 Jan 8]. p. 92. Available from: https://www.worldfishcenter.org/content/roles-andvalues-fish-rural-welfare-cambodia-welfare-data-analysis.

10. Inland Fisheries Research and Development Institute (IFReDI). Food and nutrition security vulnerability to mainstream hydropower dam development in Cambodia [Synthesis report]. Phnom Penh: The Administration; 2012. [cited 2019 Jan 8] p. 44. Available from: https://www. business-humanrights.org/sites/default/files/media/cambodia-dams-andfood-security-2013.pdf.

11. Chakriya N. Small-sized fish paste (prahoc in Khmer) processing in Cambodia [Thesis]. Phnom Penh: Royal University of Agriculture; 2010.

12. Inland Fisheries Research and Development Institute (IFReDI), Fisheries Administration. Fisheries resources in Cambodia: implications for food security, human nutrition and conversation. Phnom Penh: The Institute; 2011 [cited 2019 Jan 8]. p. 14.

13. Food and Agriculture Organization. Fish trade and human nutrition. In: Proceedings of the $14^{\text {th }}$ sub-committee on fish trade. Bergen: The Organization; 2014. [cited 2019 Jan 8]. p. 1-6. Available from: http://www. fao.org/3/a-az998e.pdf

14. WorldFish Center. The contribution of fish intake, aquaculture, and smallscale fisheries to improving nutrition: a literature review. Working Paper No. 2106. Penang: The Center; 2010. [cited 2017 Sept 20]. p. 44. Available from: http://pubs.iclarm.net/resource_centre/WF_2590.pdf.

15. Belton B, Thilsted S. Fisheries in transition: food and nutrition security implications for the global South. Global Food Secur. 2013;3:59-66.

16. Vilain C, Baran E. Nutritional and health value of fish: the case of Cambodia. Phnom Penh: WorldFish Center and Inland Fisheries Research and Development Institute (Fisheries Administration); 2016. p. 45. [cited 2019 Jan 8]. Available from: http://pubs.iclarm.net/resource centre/WF-4070.pdf.

17. Baran E, Jantunen T, Chong CK. Values of inland fisheries in the Mekong River Basin. In: Nieland AE, Béné $C$, editors. Tropical river fisheries valuation. Phnom Penh: WorldFish Center; 2007. [cited 2017 Sept 20]. Available from: https://www.researchgate.net/publication/23550993_Values_of_Inland_ Fisheries_in_the_Mekong_River_Basin.

18. The World Bank Group. Tonle Sap experience and lessons learned [Analysis in brief]. Washington DC: The Bank; 2006. p. 407-19. [cited 2017 Sept 20]. Available from: http://www.worldlakes.org/uploads/Tonle_Sap_Brief_2 OJan04.pdf.

19. Craig JF. Freshwater fisheries ecology. New York: Wiley; 2016.

20. Welcomme RL. Fisheries governance and management. In: Craig JF, editor Freshwater fisheries ecology. New York: Wiley; 2016. p. 469-82.

21. Evans PT, Sophana V. Lessons from the participatory natural resource management. In: Torell M, Salamanca AM, Ratner BD, editors. Wetlands management in Cambodia: socio-economic, ecological, and policy perspectives. Penang: WorldFish Center; 2004. p. 27-9. [cited 2017 Sept 20]. Available from: https://www.researchgate.net/publication/23550923 Wetlands_management_in_Cambodia_socioeconomic_ecological_and_ policy perspectives.

22. Lamberts D. The Tonle Sap Lake as a productive ecosystem. Int J Water Resour Dev. 2006:22(3):481-95.

23. VNP Z, Thuok N, Nuov S. Status of the Cambodian inland capture fisheries sector with special reference to the Tonle Sap Great Lake. In: Cambodia fisheries technical paper sieres volume III. Phnom Penh: Inland Fisheries 
Research and Development Institute; 2001. [cited 2017 Sept 20]. Available from http://www.mekonginfo.org/assets/midocs/0002802-biota-status-ofthe-cambodian-inland-capture-fisheries-sector-with-special-reference-to-thetonle-sap-great-lake.pdf.

24. LeGrand K, Buntong B, Chuong T, Kong T, Miller GD, Trexler CJ, et al. Leveraging shared interests to advance sustainable food safety systems in Cambodia. J Rural Community Dev. 2018;13(3):167-91.

25. United States Agency for International Development. An analysis of three commodity value chains in Cambodia: rice, horticulture, and aquaculture [Leveraging Economic Opportunities report]. Phnom Penh: ACDINOCA DAC (Dynamic Action Consulting); 2015. [cited 2016 Oct 27]. Available from: http://www.fao.org/sustainable-food-value-chains/ library/details/en/c/383724/.

26. Food and Agriculture Organization Regional Office for Asia and the Pacific The production and use of low value/trash fish from marine fisheries in the Asia-Pacific region. Bangkok: The Organization; 2005. [cited 2017 Sept 20].

27. Hortle KG, Lieng S, Valbo-Jorgensen J. An introduction to Cambodia's inland fisheries. In: Addison V, editor. Mekong development series No. 4; 2004. p. 41. [cited 2017 Sept 20]. Available from: http://www.mrcmekong.org/assets/ Publications/report-management-develop/Mek-Dev-No4-Mekong-FisheriesCambodia-Eng.pdf.

28. Food and Agriculture Organization of the United Nations. FAO species identification field guide for fishery purposes, fishes of the Cambodian Mekong. Rome: The Organization; 1996. [cited 2017 Sept 20]. Available at: http://www.fao.org/3/v8731e/v8731e00.htm.

29. Van Veen AG. Fish preservation in Southeast Asia. In: Mrak EM, Stewart GF, editors. Advances in food research. Cambridge: Academic Press; 1953. p. 209-31.

30. Tangcy M. Fisheries administration inspector, General Department of Fisheries, Royal Government of Cambodia. [2017 Sept 29]. Personal interview with $\mathrm{Da} G \mathrm{GN}$.

31. World Fish / IFReDI. Biological reviews of important Cambodian fish species, based on fishbase 2004 Volume 1. Phnom Penh: The organization; 2004. [cited 2017 Sept 20]. Available from: https://www.worldfishcenter.org/ content/biological-reviews-important-cambodian-fish-species-basedfishbase-2004-volume-1-1.

32. An authentic Khmer prahok ktis recipe. Destination Cambodia. [blog on internet]. Battambang, Cambodia. In: Carter T, blogger. Grandtourismo. 2014 [cited 2016 April 21]. Available from: http://grantourismotravels.com/2 014/11/27/authentic-khmer-prahok-ktis-recipe/.

33. Endo A. Fermented foods: fermentations of East and Southeast Asia. In: Batt CA, Robinson R, editors. Encyclopedia of food microbiology. 2nd ed. Oxford: Academic Press; 2014. p. 846-51.

34. Deak T. Handbook of food spoilage yeasts. 2nd ed. Boca Raton: CRC Press; 2007

35. Chuon MR, Shiomoto M, Koyanagi T, Sasaki T, Michihata T, Chan S, et al. Microbial and chemical properties of Cambodian traditional fermented fish products. J Sci Food Agric. 2014;94(6):1124-31.

36. Chung SY, Lee EH. The taste compounds fermented Acetes chinensis. Korean J Fish Aquat Sci. 1976;9(2):79-110.

37. Steinkraus K. Handbook of indigenous fermented foods, revised and expanded. 2nd ed. Boca Raton: CRC Press; 1995.

38. Lee JG, Choe WK. Studies on the variation of microflora during the fermentation of anchovy, Engraulis japonica. Korean J Fish Aquat Sci. 1974; 7(3):105-14.

39. Mheen T. Microbiology of salt-fermented fishery products in Korea. In: Lee $\mathrm{CH}$, Steinkraus KH, Reilly PJA, editors. Fish fermentation technology. Tokyo: United Nations University Press; 1993. p. 231-47.

40. Schwartz RD, Keller FA. Acetic acid production by Clostridium thermoaceticum in pH-controlled batch fermentations at acidic pH. App Environ Microbiol. 1982;43(6):1385-92

41. Poilane I, Karjalainen T, Barc MC, Bourlioux P, Collignon A. Protease activity of Clostridium difficile strains. Can J Microbiol. 1998;44(2):157-61.

42. Satomi M, Kimura B, Mizoi M, Sato T, Fujii T. Tetragenococcus muriaticus sp. nov., a new moderately halophilic lactic acid bacterium isolated from fermented squid liver sauce. Int J Syst Evol Microbiol. 1997:47(3):832-6.

43. Satomi M, Furushita M, Oikawa H, Yoshikawa-Takahashi M, Yano Y. Analysis of a $30 \mathrm{kbp}$ plasmid encoding histidine decarboxylase gene in Tetragenococcus halophilus isolated from fish sauce. Int J Food Microbiol. 2008;126:202-9.
44. Kobayashi T, Kimura B, Fujii T. Differentiation of Tetragenococcus populations occurring in products and manufacturing processes of puffer fish ovaries fermented with rice-bran. Int J Food Microbiol. 2000;56:211-8.

45. Kobayashi T, Kajiwara M, Wahyuni M, Kitakado T, Hamada-Sato N, Imada C, et al. Isolation and characterization of halophilic lactic acid bacteria isolated from "terasi" shrimp paste: a traditional fermented seafood product in Indonesia. J Gen Appl Microbiol. 2003;49(5):279-86.

46. Kuda T, Tanibe R, Mori M, Take H, Michihata T, Yano T, et al. Microbial and chemical properties of aji-no-susu, a traditional fermented fish with rice product in the Noto Peninsula, Japan. Fish Sci. 2009;75(6):1499-506.

47. Sarojnalini C, Suchitra T. Microbial profile of starter culture fermented fish product "Ngari" of Manipur. Indian J Fish. 2009;56:123-7.

48. Udomsil N, Rodtong S, Tanasupawat S, Yongsawatdigul J. Proteinaseproducing halophilic lactic acid bacteria isolated from fish sauce fermentation and their ability to produce volatile compounds. Int J Food Microbiol. 2010;141:186-94.

49. Thongsanit J, Tanasupawat S, Keeratipibul S, Jatikavanich S. Characterization and identification of Tetragenococcus halophilus and Tetragenococcus muriaticus strains from fish sauce (Nam-pla). Jpn J Lactic Acid Bact. 2002; 13(1):46-52.

50. Leisner JJ, Pot B, Christensen H, Rusul G, Olsen JE, Wee BW, et al. Identification of lactic acid bacteria from chili bo, a Malaysian food ingredient. Appl Environ Microbiol. 1999;65(2):599-605.

51. Cho GS, Do HK. Isolation and identification of lactic acid bacteria isolated from a traditional jeotgal product in Korea. Ocean Sci J. 2006;41(2):113-9.

52. Saithong $\mathrm{P}$, Panthavee $\mathrm{W}$, Boonyaratanakornkit $\mathrm{M}$, Sikkhamondhol C. Use of a starter culture of lactic acid bacteria in plaa-som, a Thai fermented fish. J Biosci Bioeng. 2010;110(5):553-7.

53. Thwe SM, Kobayashi T, Luan T, Shirai T, Onodera M, Hamada-Sato N, et al. Isolation, characterization, and utilization of $\gamma$-aminobutyric acid (GABA)producing lactic acid bacteria from Myanmar fishery products fermented with boiled rice. Fish Sci. 2011;77(2):279-88.

54. Sanchez PC. Philippine fermented foods: principles and technology. Quezon City: University of the Philippines Press; 2008.

55. Owens J, Mendoza L. Enzymically hydrolysed and bacterially fermented fishery products. Int J Food Sci Technol. 1985;20(3):273-93.

56. Casaburi A, Di Monaco R, Cavella S, Toldrá F, Ercolini D, Villani F. Proteolytic and lipolytic starter cultures and their effect on traditional fermented sausages ripening and sensory traits. Food Microbiol. 2008;25(2):335-47.

57. Johansson G, Berdagué JL, Larsson M, Tran N, Borch E. Lipolysis, proteolysis and formation of volatile components during ripening of a fermented sausage with Pediococcus pentosaceus and Staphylococcus xylosus as starter cultures. Meat Sci. 1994;38(2):203-18.

58. Vanna S. Fish markets in Phnom Penh, Siem Reap and Sihanouk Ville. Department of Fisheries, Mineistry of Agriculture, Forestry and Fisheries report. Post-harvest fisheries livelihood project report. Phnom Penh: The Ministry; 2005. p. 53.

59. Vannak C. Fishermen seeing fruitful prahok season, almost doubling last year's catch. Phnom Penh: Khmer Times; 2018. Sect. Business.

\section{Publisher's Note}

Springer Nature remains neutral with regard to jurisdictional claims in published maps and institutional affiliations.

Ready to submit your research? Choose BMC and benefit from:

- fast, convenient online submission

- thorough peer review by experienced researchers in your field

- rapid publication on acceptance

- support for research data, including large and complex data types

- gold Open Access which fosters wider collaboration and increased citations

- maximum visibility for your research: over $100 \mathrm{M}$ website views per year

At BMC, research is always in progress.

Learn more biomedcentral.com/submissions 